\title{
Estudio filológico-literario comparativo del relato del funeral de Augusto contado por el biógrafo Suetonio (Aug.100) y por el historiador Tácito (Ann.1.8-10)
}

\author{
Vitalino VALCÁRCEL MARTÍNEZ \\ Universidad del País Vasco - E.H.U. \\ vitalino.valcarcel@ehu.es
}

Recibido: 10 de marzo de 2015

Aceptado: 8 de abril de 2015

\section{RESUMEN}

Este trabajo se propone el análisis comparativo, bajo el punto de vista filológico y literario, del relato del funeral de Augusto en el biógrafo Suetonio (Aug.100) y en el historiador Tácito (Ann.1.8-10). En primer lugar se remarca la importancia política y social del funus publicum en Roma, objeto del relato. Sigue un detenido y minucioso análisis en el que se trata de poner de relieve las semejanzas y, sobre todo, las diferencias entre el relato de Suetonio y el de Tácito en cuanto a los datos aportados, la secuenciación de los mismos y, especialmente, en cuanto a la focalización que sobre ellos y sobre el conjunto del relato muestran uno y otro autor. Finalmente se trata de explicar las diferencias, importantes, entre ambos relatos en virtud del género literario (biografía-historia), de la intención y propósito concretos de cada una de las dos obras (Vita Augusti de Suetonio y Annales de Tácito) y de la distinta personalidad intelectual de cada uno de los dos autores.

Palabras clave: Historiografía. Biografía. Tácito. Suetonio. Funeral de Augusto.

ValCÁRcel Martínez, V., «Estudio filológico-literario comparativo del relato del funeral de Augusto contado por el biógrafo Suetonio (Aug.100) y por el historiador Tácito (Ann.1.8-10)», Cuad. Fil. Clás. Estud. Lat. 35.1 (2015) 43-77.

A comparative analysis, under philological and literary point of view, of the account of Augustus' funeral written by the biographer

Suetonius (Aug.100) and by historian Tacitus (Ann.1.8-10)

\begin{abstract}
This paper aims to make a comparative analysis, under a philological and literary point of view, of the account of Augustus' funeral written by the biographer Suetonius (Aug.100) and by historian Tacitus (Ann.1.8-10). Firstly, the political and social importance of the funus publicum, the subject of the account, is highlighted. Secondly, there is a very detailed analysis which tries to emphasize the similarities and, specially, the differences between both Suetonius' and Tacitus' account in relation to the provided data
\end{abstract}


and its sequence and, particulary, in relation to focalization that each author proves concerning that data and the account as a whole. Finally, this paper tries to explain the significant differences between both accounts by reason of their literary gender (biography-history), the intention and specific purpose of each work (Suetonius' Vita Augusti and Tacitus' Annales) and the different intellectual personality of each author.

Keywords: Historiography. Biography. Tacitus. Suetonius. Augustus’ funeral.

Sumario: 1. Por qué el funus publicum (imperatorium) romano es objeto de noticia histórica y biográfica. 2. Análisis comparativo del relato que del funus publicum de Augusto nos han trasmitido el biógrafo Suetonio y el historiador Tácito. 3. Razones explicativas de la individualidad y diferencia de cada uno de los dos relatos en virtud del género, del propósito de cada obra y de la personalidad intelectual de cada uno de los autores. 4. Referencias bibliográficas. 5. Apéndice I: Esquema comparativo de ambos relatos. 6. Apéndice II: Sobre la interpretación de TAC.Ann.1.8: remisit Caesar adroganti moderatione.

\section{POR QUÉ EL FUNUS PUBLICUM (IMPERATORIUM) ROMANO ES OBJETO DE NOTICIA HISTÓRICA Y BIOGRÁFICA}

En la Antigüedad Clásica la historiografía y, de otro lado, la biografía constituyen dos géneros que con mucha frecuencia se entrecruzan, aun teniendo los autores de las obras, principalmente los biógrafos, una cierta conciencia de que son dos géneros distintos, que obedecen a pautas literarias diferentes ${ }^{1}$. Y, por otra parte, en muchas ocasiones la biografía política y la historia tratan un mismo asunto o tema, aquél en el que el protagonista común a una Vida y a la historia de su polis, sea gobernante, militar o legislador, tuvo parte activa o incluso la responsabilidad mayor en los asuntos políticos y militares del momento. Pues bien, será entonces interesante examinar el tratamiento o enfoque de un tema o asunto concreto, común a uno y otro género, es decir, el episodio de una Vida y su correlato historiográfico, en nuestro caso no tanto para completar la información histórica cuanto para ver las diferencias de tratamiento de dicho tema.

Nosotros nos proponemos, pues, examinar aquí la noticia de un episodio histórico muy concreto y particular, el funeral del emperador Augusto, tal como nos lo ofrecen, de un lado, un biógrafo y una Vida muy concretos, Suetonio en su Vida de Augusto y, de otro lado, un historiador y una obra igualmente muy concretos, Tácito en sus Anales $^{2}$. El contraste entre la noticia de uno y otro autor pondrá de relieve, esperamos, tanto la diferencia entre ambos géneros y la ambigua relación que los une, como la distinta personalidad de los autores y especialmente los propósitos, diferentes, de

\footnotetext{
${ }^{1}$ La bibliografía sobre ésta que podríamos llamar quaestio uexata en la historia literaria de las épocas antigua, medieval y renacentista es, como puede suponerse, abundante. Perdóneseme remitir al lector a un trabajo nuestro en el que se encuentran las referencias a buena parte de esa bibliografía: Valcárcel 2009, pp.19-39.

${ }^{2}$ En ocasiones acudiremos a los historiadores Dión Casio, Apiano o Herodiano para contrastar algún dato concreto.
} 
cada una de las obras en cuestión con la repercusión que ello tiene en la elaboración de la noticia.

Por otra parte, creemos que la noticia sobre el funeral de Augusto es una noticia importante y de porte histórico porque el momento de la muerte y de los últimos homenajes (o ultrajes) de un monarca o de un emperador suponen un momento políticamente significativo. Los ritos del funeral público, en efecto, forman parte de un drama político en el que están implicadas muchas de las personas poderosas en la sociedad. Por ello la noticia de tal hecho se ha recogido muchas veces en la historia política. Y, naturalmente, tampoco extrañará que esa noticia, más o menos desarrollada, figure en la biografía de los personajes políticos de más relieve ${ }^{3}$. Efectivamente, en las horas o días posteriores al fallecimiento del monarca o emperador puede surgir un cierto grado de incertidumbre, una sensación de vacío de poder, y un cierto peligro para la continuidad de una monarquía, pues a veces la línea o sucesión monárquica no está del todo fijada ${ }^{4}$. Ello conlleva momentos de miedos para unos y esperanzas para otros, especialmente para aquellos que se mueven en el entorno del poder. Un momento de éstos es el que vive Roma cuando se acerca la muerte de Augusto, momento que Tácito nos presenta epigramáticamente y con la plasticidad que solo su pluma puede lograr: postquam provecta iam senectus (Augusti) aegro et corpore fatigabatur aderatque finis et spes novae, pauci bona libertatis in cassum disserere, plures bellum pavescere, alii cupere (Ann.1.4). Lo cual lleva a oscuridades y manipulaciones a la hora de comunicar la noticia de la muerte. Para no salir del caso de Roma y de Augusto recordemos cómo Tácito nos habla del oscuro comportamiento de Livia en los momentos finales de Augusto $^{5}$ : ella restringe el acceso de quienes pueden tener información sobre el estado de salud de Augusto hasta tener las cosas preparadas para que todo sea más fácil para el sucesor que ella pretende, Tiberio ${ }^{6}$. Y muy parecida es la situación que nos describen Tácito (Ann.12.68-69) y Suetonio (Claud.45) sobre el comportamiento de Agripina en la muerte de Claudio. De modo que en esas situaciones las honras fúnebres, el funeral, sus ritos y las manifestaciones de dolor adquieren, por su simbolismo, un importante relieve y significado, forman

\footnotetext{
${ }^{3}$ Algunos datos concretos relativos a este hecho pueden verse en las páginas que desarrollan el n $n^{\circ} 3$ de nuestro sumario.

${ }^{4}$ Precisamente en su Vida de Augusto (cap.99) nos dice Suetonio que el emperador, ya moribundo (justamente en el último día de su vida), preguntaba a menudo si se observaba en la calle señales de agitación a causa de su estado: supremo die identidem exquirens an iam de se tumultus foris esset. N.B. Para el texto de Suetonio utilizamos la edición de Ailloud (1989).

$\mathrm{Y}$, aunque con interesada hipérbole, Veleyo Patérculo nos retrata así los momentos que siguieron a la muerte de Augusto: quid tunc homines timuerint, quae senatus trepidatio, quae populi confusio, quis orbis metus, in quam arto salutis exitiique fuerimus confinio, neque mihi tam festinanti exprimere vacat neque cui vacat potest. Id solum voce publica dixisse habeo: cuius orbis ruinam timueramus eum ne commotum quidem sensimus (2.124.1; ed. de Stegman de Pritzwald).

${ }^{5}$ Ann.1.5: acribus namque custodiis domum et vias saepserat Livia, laetique interdum nuntii vulgabantur, donec provisis quae tempus monebat simul excessisse Augustum et rerum potiri Neronem fama eadem tulit. N.B. Para el texto de los Anales utilizamos la edición de Fisher (1966).

${ }^{6}$ Comportamiento sobre el que, por cierto, es más explícito Dión Casio Hist.1.46. cap.31, el cual, alude a la división de las fuentes respecto a este punto.
} 
parte de un drama político en el que, como dijimos, están implicadas muchas personas (Huntington - Metcalf 1979, p.122). Como prueba de su importancia podemos ver el hecho de que Tiberio en el primer edicto que, como tribuno, promulgó nada más morir Augusto dice que él en los días siguientes solo se ocupará de organizar los funerales y de velar el cadáver de Augusto: verba edicti fuere pauca et sensu permodesto: de honoribus parentis consulturum, neque abscedere a corpore idque unum ex publicis muneribus usurpare (Ann.1.7). De hecho a veces el funeral público es objeto de vivo debate político. Ese debate, que tiene lugar en el Senado, comenzaría por discutir si se aprueba o no el funus publicum ${ }^{7}$ para el difunto, el mayor honor que Roma le puede conceder ${ }^{8}$; y se debatirían después los mandata de funere en el caso de que el protagonista los hubiera dejado expresos como sucedió, entre otros, en los casos de Sila (Weinstock 1971, pp.348-349) ${ }^{9}$, de César ${ }^{10}$ y de Augusto ${ }^{11}$, el cual verosímilmente había tenido en cuenta el funeral de Sila. Y recuérdese cómo los asesinos de César, encabezados por Bruto y Casio, tratan de impedir, porque saben lo que les va en ello, que César tenga un funus publicum, incluso un funeral privado, puesto que pretendían arrojar su cadáver al Tíber: fuerat animus coniuratis corpus occisi in Tiberim trahere... (SUET.Iul.82.4). Y Cicerón nos dejó un muy claro testimonio de la conciencia que todos tienen de la importancia de que se celebre o no un funeral público para César cuando el 19 de abril del 44 a. C. le escribe a su amigo Ático: meministine te clamare causam perisse si funere (Caesar) elatus esset? (CIC. Epist. Att.14.10.1) $)^{12}$.

Y es que, como dice J. Arce (1988, p.40), después de Sila el funus publicum se había convertido en Roma en un acto colectivo de exaltación que todos deben contemplar y al que todos deben adherirse porque forma parte del ritual del poder; y ese funus sanciona de algún modo la conducta pública del gobernante cuyas honras fúnebres se celebran. Por esta causa los funerales públicos en Roma suponían un minuciosa preparación y de ellos importan casi todos los detalles: la translatio cadaueris (si la muerte ha tenido lugar fuera de Roma), de qué modo se discuten y aprueban o se

\footnotetext{
${ }^{7}$ En las páginas que siguen entendemos el concepto 'funeral público' / 'funerales' (lat. funus publicum, funera) en su sentido más general y amplio, pudiendo abarcar, según el contexto, las exsequiae, el iustitium, las distintas manifestaciones de luctus y los signos de la futura apoteosis. Incluye igualmente la translatio cadaueris a Roma, cuando la muerte (como en el caso de Augusto) tiene lugar fuera de la Vrbs. Además estos hechos principales conllevan toda una serie de pasos diversos, de ceremonias y de medidas político-sociales que, en general, son bien conocidos.

${ }^{8}$ Cicerón nos transmite en sus Filípicas (9.7.15-16) el texto del edicto de concesión del funeral público a Servio Sulpicio Rufo. Es un documento sumamente aclarador de lo que en Roma supone un funus publicum.

${ }^{9}$ Por Apiano (Hist.2; Bellum civile,1.105-106) conocemos bien el debate que el funeral de Sila suscitó en el Senado.

${ }^{10}$ Cosa que sabemos por Dión Casio, Hist.56.33.1. Desde el funeral de Sila no había habido otro funus publicum en Roma hasta el de César. $C f$. Weinstock (1971, p.350).

${ }^{11}$ Cf. SuEt.Aug.101: Tribus uoluminibus, uno mandata de funere suo complexus est. Véase igualmente Dión Casio, Hist.54.28.5.

${ }^{12}$ Hay que recordar que la aprobación del funus publicum para César conectaba necesariamente con la validez de los actos de gobierno del mismo y con la validez de su testamento. $C f$. Fraschetti (1990 p.48); interesa para el tema aquí tratado todo el c.2 («Il tempo del lutto»).
} 
modifican y completan en el Senado ${ }^{13}$ los mandata de funere que el princeps muerto dejaba escritos ${ }^{14}$, quién es el encargado de organizar el funeral ${ }^{15}$, si hay peligro de tumulto, el luto público o iustitium (así llamado en la época imperial), cómo es el cortejo fúnebre, por ej., qué lugar ocupan en él la familia o los mandatarios; el recorrido que sigue ese cortejo, qué discursos fúnebres va a haber, quién o quienes los pronuncian y dónde se pronuncian, el lugar de la cremación, o inhumación, signos que preanuncian la divinización y tantos detalles más como el lugar y la clase de sepulcro.

Y en congruencia con lo dicho, no es de extrañar que exista una ya larga tradición de estudio sobre los funerales romanos en general ${ }^{16} \mathrm{y}$ sobre el funus publicum/funus imperatorium en particular ${ }^{17}$ así como sobre la laudatio funebris, el culto imperial, la consecratio o la figura de Augusto.Y, claro está, otro tanto ocurre para las obras de Tácito y de Suetonio ${ }^{18}$. Por ello es claro que muchos (por no decir todos) de los hechos mencionados por estos autores en su relato del funeral han sido estudiados de algún modo: algunos per se, otros brevemente comentados en obras de carácter general. Y ello bajo diferentes puntos de vista, según los casos: el histórico, el religioso, el sociológico, el antropológico, etc. Pero lo que no conozco es un estudio con una confrontación sistemática de la noticia en ambos autores y, menos, bajo la perspectiva filológico-literaria y con el propósito que ahora lo hacemos. Y puesto que, según decíamos, nuestro principal objetivo es el de analizar cómo se plantean las noticias del

${ }^{13}$ Fruto de esa discusión en el Senado suele ser un senadoconsulto relativo a las honras fúnebres en cuestión, pero en el caso de Augusto no conocemos tal senadoconsulto.

${ }^{14}$ Los romanos, en general, creían que la muerte no implicaba la disolución total de su ser, el cual, de un modo u otro, pasaba a vivir bajo tierra ( $c f$. por ej., Cic.Tusc.1.16). Ello conllevaba que dieran una gran importancia a no morir sin sepultura y a tener unas exequias solemnes. De ahí que se preocupen de dejar por escrito sus instrucciones concretas (mandata de funere), con la designación de la persona encargada de llevarlas a cabo, la provisión de fondos para los gastos del funeral, etc. Es decir, era normal en Roma que el muerto dejara señalado en su testamento el formato del funeral. Petronio en su Satiricón (71.4-72. 2) parodia este hecho al hacer leer a Trimalción su testamento en el cual da instrucciones precisas y detalladas sobre cómo ha de ser su tumba (Davies 2000, pp.4 y 8).

15 Aunque de una época muy posterior, es revelador lo que Amiano Marcelino (21.16.21) nos dice a propósito del engreimiento de Joviano por haber sido encargado del funeral de Constancio II.

16 Sólo queremos señalar ahora unos pocos títulos para nosotros más significativos y de carácter más general sobre los funerales en Roma. A lo largo del trabajo se irán señalando otros más específicos tanto sobre aspectos concretos de los funerales como sobre los otros conceptos arriba mencionados. Un primer acercamiento a lo que suponía para los romanos el hecho del funeral, las distintas clases del mismo, su evolución histórica, etc., tenemos en el aún importante y bien documentado artículo «Funus», en el Dictionaire des Antiquités grecques et romaines de Daremberg - Saglio. Y por lo que hace al funus publicum señalaré ahora solamente tres trabajos: Vollmer (1892-1893, pp.320-364); Weinstock (1971), el cual dedica unas muy interesantes páginas (pp.347364) al tema de los funerales de César; y Arce 1988, obra citada antes y que supone un excelente estudio que trata el tema anunciado de una manera global y a la vez penetrante y con una rica y actualizada bibliografía.

${ }^{17}$ Utilizamos generalmente el término funus publicum en lugar de funus imperatorium en razón a que en la época imperial ambos términos son equivalentes (Arce 1988, pp. 27 y 40).

${ }^{18}$ Como el lector sabe, la bibliografía sobre estos dos autores, especialmente sobre Tácito, es inmensa. En el caso de este último autor baste ahora con remitir a $A N R W$, II,33,2(1990) y a II,33,4 (1991). En el primero de estos vols. se encuentran los capítulos de Suerbaum (1990, pp.1032-1476) y el de Benario (1990, pp.14771498) con sendas bibliografías sobre el historiador latino. Para los años posteriores a 1990 puede verse Pagán (2012) en su bibliografía final. Para Suetonio véase nuestra n. 29. Nosotros a lo largo del trabajo señalaremos solo aquella bibliografía que hayamos usado y nos parezca pertinente al tema que nos ocupa. 
funeral de Augusto, de un lado Tácito, el historiador, y, de otro Suetonio, el biógrafo, lógicamente ello nos obligará, por una parte, a tocar los principales hechos del funeral y de su significado político pero, sobre todo, nos llevará a examinar y contrastar el relato que de los mismos hacen ambos autores poniendo de relieve la diferencia de intereses y de focalización, con sus consecuencias literarias, entre uno y otro.

\section{ANÁLISIS COMPARATIVO DEL RELATO QUE DEL FUNUS PUBLICUM DE AUGUSTO NOS HAN TRASMITIDO EL BIÓGRAFO SUETONIO Y EL HISTORIADOR TÁCITO}

Pues bien, ¿cómo tratan todo esto dos autores romanos de prestigio cierto, aunque desigual, el historiador Tácito y el biógrafo Suetonio, a propósito del funeral de Augusto? Naturalmente todo debe comenzar por una atenta lectura de los correspondientes relatos de ambos autores, relatos de los que, como apoyo a la lectura del trabajo, presento un esquema o cuadro sinóptico (Apéndice I), hecho para la ocasión, en el que confronto los datos que uno y otro autor nos ofrecen; en él, con una rápida ojeada panorámica, se pueden ver las similitudes, pero también, y ello es más importante para nuestro propósito, las diferencias.

Suetonio comienza (Apdo. I) ${ }^{19}$ el tema del relato del funeral con la translatio cadaueris de Augusto $^{20}$. En orden cronológico Suetonio se refiere, de forma rápida, al recorrido que sigue el cortejo fúnebre llevando, a través de los pueblos de la Campania

${ }^{19}$ En el estudio que sigue analizaremos los datos de ambas noticias siguiendo el orden establecido en el mencionado esquema (Apéndice I).

${ }^{20}$ En la estructura externa o división de capítulos tradicional el capítulo de la Vita Augusti que versa sobre los funerales del emperador, el cap. 100, dedica su primer párrafo a la fecha de la muerte, la cual data de forma absoluta y relativa. Ahora bien, es sabido que la división en capítulos de las Vidas suetonianas se debe a los humanistas del Renacimiento y que fue consagrada por Erasmo en su edición de 1518. Esta división sigue siendo hoy la 'vulgata', si bien algunas ediciones críticas modernas (Roth 1858; Ailloud 1989) indican también la división en capítulos del códice Memmianus (s.IX), que es el ms. más antiguo y más fiel de cuantos se han conservado de las Vitae de Suetonio. Por nuestra parte, con el fin de averiguar si Suetonio en la configuración de sus unidades temáticas vincula la datación de la muerte a la noticia sobre ésta o a los hechos que siguen a la misma, como los funerales, hemos realizado un recorrido comparativo de las diferentes vidas en relación a este punto. En él nos hemos fijado en criterios más internos que las meras capitulaciones de las ediciones críticas como son los que están implícitos en el modo gramatical y estilístico de introducir la datación: qué palabra (verbo: obiit, periit, uixit, excessit, se traiecit, extinctus est, occisus est) encabeza la noticia de la datación, si ésta va tras pausa fuerte o no, si introduce una oración principal o dependiente, si da lugar a una oración simple o compleja. Las conclusiones provisionales al respecto son: que la datación de la muerte del emperador, por sí sola, no conforma una rúbrica de la vita; que esa datación en unas ocasiones forma parte de la noticia de la muerte mientras que en otras se vincula a la noticia de los funerales (públicos o privados) y/o enterramiento o a la noticia de la reacción de la gente o del Senado o al presagio de la muerte. En el caso de la Vita Augusti creemos que la fecha de la muerte de Augusto cierra, de forma conceptualmente lógica, la noticia del último día de Augusto y de cómo murió. Por ello, y a falta de datos gramaticales más aclaradores, la vemos más vinculada a la rúbrica de la muerte que a la de los funerales. De hecho, el mencionado códice Memmianus asignaba esa noticia a la unidad anterior y el editor M. Ihm (1908), aun respetando la convención de incluirla en el cap. 100 (funerales), separa la datación de la muerte de la translatio cadaueris con punto y aparte, cosa que no hace entre la noticia de su muerte y la de su datación. 
y del Lacio, el cadáver del emperador desde Nola hasta la Vrbs y hasta el vestíbulo de la propia casa de Augusto, la domus augustana, sencilla casa privada en el Palatino ${ }^{21}$. En esta noticia de la translatio el biógrafo destaca el rango social de quienes transportan el cadáver, los decuriones municipiorum et coloniarum y el equester ordo ${ }^{22}$, y que aquél sea depositado en la basílica o en el templo más importante de cada ciudad ${ }^{23}$; además precisa que el cadáver era transportado por las noches propter anni tempus ${ }^{24}$. Y es significativo el hecho de que, a pesar de la rapidez de esta noticia ${ }^{25}$, la translatio de Augusto es la de mayor entidad de cuantas aparecen en las Vidas suetonianas ${ }^{26}$.

Por el contrario el historiador Tácito prescinde de este apartado, lo cual supone una omisión reveladora pero que, pensamos, ha de explicarse no tanto por la diferencia de género literario cuanto por los intereses particulares en este momento de su obra puesto que Tácito en sus Anales sí se detiene ampliamente en narrarnos la translatio de los cineres Germanici ${ }^{27}$. Ello se debe más bien al propósito y diseño general a que obedecen los Anales, sobre los que versaremos brevemente más adelante, propósito en el que, por cierto, cuenta de forma importante la velocitas a la que, para lo referente a Augusto, Tácito se había obligado; y a todo ello habría que añadir la distinta simpatía política que a Tácito le merecen uno y otro personaje, sin excluir, además, la inmensa popularidad de que Germánico gozó en la Roma de su tiempo ${ }^{28}$.

${ }^{21}$ Sobre su ubicación, sencillez inicial y las transformaciones de que fue objeto, tras la muerte de Augusto, puede verse Paoli (1964, pp.25-26) y Roldán (2008, pp.148-149).

${ }^{22}$ Esta noticia halla su complemento en Claud. 6.1, lugar en que Suetonio señala que para transportar el féretro de Augusto el estamento ecuestre solicitó permiso a los cónsules por medio de Claudio. Más tarde Suetonio vuelve a poner de relieve la participación del orden ecuestre a la hora de recoger los restos de Augusto después de la crematio. No es descartable, pues, que este doble recuerdo para el orden ecuestre enlace con la posible ideología filoecuestre del biógrafo latino. Sobre la misma, $c f$. Picirilli (1998, pp.184-187).

${ }^{23}$ Una explicación de por qué en este caso el cadáver, en principio cosa 'contaminada', podía ser depositado en los templos puede verse en Fraschetti (1990, p.73).

${ }^{24}$ Suetonio especifica que el hecho de que el cortejo fúnebre avance hacia Roma por las noches (noctibus) se debía al afán de evitar el calor del día (propter anni tempus). Pero Scheid (1984, p.125) piensa que Suetonio se confunde en esto, ignorando el significado profundo de este hecho y que no sería otro que el de obrar según la vieja costumbre de celebrar los funerales de noche con el fin de evitar que sacerdotes y magistrados se hicieran impuros al entrar en contacto con un cortejo fúnebre.

${ }^{25}$ Parecida en extensión a la que nos da Dión Casio, también parca en este punto, a pesar del gran detalle y detenimiento con el que el historiador griego nos relata los funerales de Augusto (Dión Casio, Hist.7. 30-47); y muy lejos ambas, en extensión, de la que acerca de la translatio de Sila nos proporciona Apiano (Bellum civile,1.105-106).

${ }^{26}$ La referida a Tiberio (Tib.75.3) se queda en una mera alusión; y la de Druso I (Tib.7. 3 y Claud.1), aunque un poco más extensa que la de aquél, tampoco llega a tener la entidad de ésta de Augusto. De otro lado, extraña que, a pesar de la larga noticia (minibiografía) que Suetonio nos ofrece de Germánico en su Vida de Calígula (caps. 1-7) y a pesar del espacio que, dentro de ella, dedica a los signos de duelo que los romanos manifestaron por su muerte, no aluda a la histórica e impactante translatio de la urna con las cenizas de Germánico desde Antioquía a Roma.

${ }^{27}$ Muy extensa y emotiva es la narración que de la traslación de los cineres Germanici nos ofrece Tácito en Ann.3.1-6. Por otra parte, Tácito narra también ahí, criticando a Tiberio, las humildes exequias de Germánico.

${ }^{28}$ Sobre tal popularidad y sobre la interpretación de los signos y manifestaciones de dolor que, según Tácito, Suetonio y otros testimonios menores, se dieron en Roma a la muerte de Germánico versa, con amplitud y profundidad, Versnel (1980, pp.541-618). Este autor afirma: «it is no exaggeration to state that Germanicus was the most popular of all celebrated emperors and members of imperial families» (ib., p.542). 
A continuación (Apdo. II) ambos autores versan sobre la discusión del Senado acerca de las honras fúnebres y los honores a tributar a Augusto. Pero ya en el modo de presentar la discusión uno y otro autor difieren notablemente. Suetonio nos dice que la discusión de los senadores consistió en ver quién iba más lejos en los honores que se proponían para Augusto: Senatus et in funere ornando et in memoria honoranda eo studio certatim progressus est ut... Por el contrario Tácito anuncia la discusión con una fórmula neutra, sugiriendo que la discusión no era unidireccional: tum consultatum de honoribus (Augusti). Es como si el término consultatum connotara un resquicio de aparente autonomía y libertad del Senado para deliberar en apariencia sobre si se concedía el funus público a Augusto (sólo el Senado puede concederlo oficialmente, según dijimos ya) y, con mayor seguridad y correspondencia con la realidad, para deliberar sobre los mandata de funere que Augusto había dejado escritos así como sobre las propuestas que los senadores hicieran al respecto. En lo que sí coinciden ambos autores es en anunciar al lector que realizarán una selección de los hechos que conocen dando cuenta solo de los que para ellos son los más importantes. Suetonio, antes de iniciar la secuencia de los mismos, escribe inter alia complura ${ }^{29} ; \mathrm{y}$, por su parte, Tácito lo hace con la frase: ex quis (honoribus) qui maxime insignes visi (Ann.8.1.2). Pero podemos observar que tal selección la hacen con distinto criterio. Suetonio ofrece aquellas propuestas ${ }^{30}$ que tienen que ver con la pompa y los honores del funeral de su protagonista, Augusto, así como con los signa tristia o insignia lugentium del luctus publicus que implicaba su muerte. Propuestas que senadores diversos, pero innominados (quidam ..., alii..., nonnulli..., fuit et qui..., alius) hacen en la sesión del Senado. Véase a este respecto lo que dice en $\operatorname{los} \mathrm{n}^{\mathrm{os}} 1,2,8,9,10,11$ y 12 del citado Apartado. Los detalles, ritos y ceremonias que aquí nos proporciona Suetonio ${ }^{31}$, muchos ya presentes en anteriores funerales públicos, especialmente a partir de los funerales públicos auspiciados precisamente por el propio Augusto ${ }^{32}$, adquieren relieve por el hecho de que convergen todos en dos ideas no explicitadas por Suetonio pero que se deducen de los datos mismos que nos ofrece: una, la de que el luctus publicus era sentido por toda Roma, como cuerpo social, ya que el muerto era Augusto, el otrora declarado pater patriae. De ahí

\footnotetext{
${ }^{29}$ Tenemos aquí una muestra más de cómo Suetonio no es un mero 'compilador de noticias' sino que selecciona y organiza éstas guiado por una filosofía personal y la finalidad concreta de su obra. Capacidad crítica de selección, filosofía y una cierta subjetividad de Suetonio que ponen de relieve la mayoría de los estudiosos modernos contra cierta crítica tradicional, ejemplificada, por ej., por Funaioli (1931) o Paratore (1959). Más ecuánimes y modernos estimamos los trabajos siguientes, que interesan también por su carácter general: Steidle (1963); Gugel (1977); Cizek (1977); Baldwin (1983); Wallace-Hadrill (1983) y Lounsbury (1987). Para la bibliografía sobre Suetonio, hasta el año 1988, con una revista crítica de las monografías, puede verse Galand-Hallyn (1991, pp.3576-3619).

${ }^{30}$ Siempre en el marco de la citada selección. Para una relación más amplia de de los posibles ingredientes de la pompa de un funeral público de los emperadores puede verse Vollmer (1892-1893, pp.321-364).

${ }^{31}$ Varios de los datos aquí consignados tal vez los viera Suetonio en los Acta diurna. Para el uso de los Acta Diurna por Suetonio puede verse Gascou (1984, p.490).

${ }^{32}$ Los de Marcelo, Agripa, Druso. Precisamente, al referirse al de Druso, Tácito (Ann.3.5) dice que Augusto hizo honrar a aquél con toda clase de honores: con los que venían de atrás (cuncta a maioribus reperta) pero también con otros por él usados por vez primera aut quae posteri invenerint cumulata.
} 
el cuidado que Suetonio pone en referirse a la participación en las honras fúnebres de diferentes estamentos sociales ${ }^{33}$ : participan los senadores ${ }^{34}$, los jóvenes, hijos de principales de la ciudad (canentibus nenian principum liberis utriusque sexus), el orden ecuestre, hombres y mujeres (anulos aureos ponendos aureosque sumendos ${ }^{35}$ ) sin que faltara incluso la propuesta de que también los sacerdotes de los más importantes colegios participaran recogiendo los restos de Augusto tras la cremación ${ }^{36}$. Y la otra idea que parece guiarlo en la selección de los datos es la de que, debido al fervor del Senado (senatus et in funere ornando et in memoria honoranda eo studio certatim progressus est ut...), el funeral de Augusto sobrepasó a los de ocasiones anteriores en grandiosidad, fastuosidad y manifestaciones de duelo y de reconocimiento al difunto, Augusto, repercutiendo todo ello en el correspondiente impacto social y político ${ }^{37}$. Por ello señala cosas como el que al frente del cortejo fúnebre marchara la estatua de la Victoria (praecedente Victoria quae est in curia) ${ }^{38}$ o que el cortejo fúnebre saliera al Campo de Marte por la puerta de los triumphi, hecho francamente excepcional. Y Suetonio, en una gradación ascendente, concluye la serie de honores que proponen los senadores con las dos propuestas que le parecen más llamativas: la de que se cambiara el nombre de augustus al mes de septiembre (fuit et qui suaderet apellationem.... $)^{39} \mathrm{y}$, aún más, la de que a todo el tiempo que duró su vida se le diera el nombre de 'Siglo de Augusto' (alius ut omne tempus...) ${ }^{40}$. Este segundo apartado se cierra con una transición de tono moderadamente adversativo: uerum adhibito honoribus modo. Con ella Suetonio da a entender que por fin se puso límite, verosímilmente por Tiberio, aunque Suetonio no lo dice, a la serie de propuestas que, en una especie de agon, los senadores iban haciendo para encumbrar el funeral de

${ }^{33}$ Hay que recalcar que el único componente del cuerpo social que no nombra Suetonio aquí es, como se ve, el populus.

${ }^{34}$ Senatus et in funere ornando et in memoria honoranda eo studio certatim progressus est.... Y su presencia vuelve a aparecer en Suetonio en el siguiente apartado: senatorum umeris delatus. Honor este último que, si hubiera tenido lugar, sería extraordinario, pues antes solamente Numa, 717-673 a.C. y Sila, 138-78 a.C. habían gozado del mismo. Sobre esta cuestión véase más adelante, y también nuestro Apéndice II.

${ }^{35}$ Esta propuesta no tiene por qué entenderse referida solo a los nobles pues ya desde la segunda guerra púnica también los equites podían llevar tales anillos. Y parece que los portarían también las mujeres ricas. Sobre el uso de los anillos en Roma, $c f$. Guillén (1977, pp.316-320).

${ }^{36}$ Ossa legenda per sacerdotes summorum collegiorum. Propuesta que no se llevó a cabo pues, según señalamos después, más tarde Suetonio $\left(\mathrm{n}^{\circ} 7 \mathrm{del}\right.$ Apartado III) dice que tal acción la realizaron los principales del orden ecuestre: reliquias legerunt primores equestris ordinis tunicati et discincti pedibusque nudis.

${ }^{37}$ Impacto social y político, que iba a repercutir no solo en la figura de Augusto sino también de la domus augusta, a la que esperaba un trascendente destino en la historia de Roma.

${ }^{38}$ Se trata de la estatua de la Victoria erigida en el 29 a. C. en la Curia Iulia, la nueva sede del Senado. Interpretamos que el biógrafo latino da cuenta de este detalle quizás buscando más reflejar la solemnidad del cortejo fúnebre que el significado político al que antes nos referíamos.

${ }^{39}$ Siguiendo el ejemplo de César, Augusto, probablemente en el año 27 a. C., hizo que el mensis sextilis pasara a llamarse mensis augustus dado que, según Suetonio (Aug.31.2), Dion Casio (Hist.55.6-7) y Macrobio (Sat.1.35) en ese mes habían tenido lugar sus principales victorias. Weinstock (1971, p.157) defiende como razón más verosímil otras coincidencias. Sobre éstas y otras propuestas de cambio en el nombre de los meses llevadas a cabo en el Imperio, $c f$. Talbert (1984, pp.360-364).

${ }^{40}$ Sobre el significado de saeculum como medida histórica y las implicaciones de la expresión saeculum augustum versa brevemente Weinstock (1971, pp.194-197). 
Augusto y su figura. Aunque por la rapidez con que procede nuestro biógrafo nos deja también en la duda de cuántas y cuáles de aquellas propuestas hechas fueron aprobadas y realmente cumplidas ${ }^{41}$

Y, tras aquella rapidísima transición, Suetonio avanza en la narración para señalar, ahora sí, algunas ceremonias y hechos concretos que tuvieron lugar en las exequias. El primero de ellos es el señalar las dos laudationes fúnebres de Augusto. Y en este punto muestra igualmente su interés en ser concreto y preciso: las laudationes fúnebres fueron dos ([Augustus] bifariam laudatus est), las pronunciaron Tiberio y Druso (el hijo de Tiberio) y tuvieron lugar, naturalmente, en el Foro pero la de Tiberio ante el templo de J. César (aedes diui Iulii) y la de Druso ante la vieja tribuna de los oradores, los Rostra Vetera. Como vemos, Suetonio ahora no quiere pasar por alto que las laudationes fueron, según decimos, dos en vez de una y que quienes las pronunciaron, sin duda formalmente encargados por el Senado, fueron nada menos que Tiberio, el sucesor y Druso, el hijo de este ${ }^{42}$.

Y, siguiendo el orden cronológico de los acontecimientos, Suetonio alude después a dos hechos. Uno digno de toda ponderación, a saber, que el cadáver de Augusto fue trasladado del Foro al Campo de Marte ${ }^{43}$ y, según él, a hombros de los senadores (umeris Senatorum) ${ }^{44}$. Por su parte el segundo es esperable en un funus publicum: allí, en el Campo de Marte, Augusto fue incinerado (crematusque). Pero Suetonio también camina ahora con prisa y no se detiene en otros pormenores del ritual de la incineración ${ }^{45}$.

Seguidamente nuestro biógrafo señala que un expretor ${ }^{46}$ juró haber visto subir al cielo la imagen de Augusto: nec defuit uir praetorius, qui se effigiem cremati euntem in caelum uidisse iuraret. Dato éste de Suetonio que enlaza con la posterior consecratio o divinización de Augusto, de la cual constituye solo como un preanun-

\footnotetext{
${ }^{41}$ Pero o por la coincidencia con Tácito o por las informaciones que nos da Dión Casio (Hist.42) o por constituir ritos habituales en un funus publicum se puede averiguar cuáles se llevaron a cabo.

${ }^{42}$ En sus Vidas de los Doce Césares Suetonio solo nos habla de las laudationes de Julio César, entremezcladas, según él, con la lectura del testamento de César: laudationis loco... per praeconem pronuntiavit senatus consultum ..., quibus perpauca a se uerba addidit (Iul.84); de ésta de Augusto; y de la de Tiberio por Calígula (Cal.15). En las demás Vidas de emperadores solo extraña la ausencia de la alusión a la laudatio de Claudio por Nerón, de la que Tácito nos da una relativamente amplia noticia (Ann.13.3), aunque ciertamente más focalizada en quien la pronuncia, Nerón, que en el elogiado, Claudio. Entendemos que para los otros nueve emperadores biografiados no hubo ocasión de la laudatio, dadas las características de sus reinados y/o la clase de muerte y funeral que tuvieron.

${ }^{43}$ Recuérdese que el hecho de que Augusto fuera incinerado allí suponía ya un honor, pues en él solo había lugar para los altos personajes de la historia de Roma: Sila, Hirtio, Pansa, Julio César, etc., enlazando incluso con la memoria y la leyenda de la muerte de Rómulo. (Liv.1.16.1). Cf. Davies (2000, pp.137-140).

${ }^{44}$ Afirmación escueta y rotunda por parte de Suetonio. Pero sobre ella volveremos más tarde al referirnos a la alusión que Tácito hace a esta circunstancia. $C f$. también nuestro Apéndice II.

${ }^{45}$ Nótese lo dicho antes acerca de que también Suetonio procede con discriminación, seleccionando los hechos a tener en cuenta. Y, por supuesto, tampoco él menciona elementos habituales de la pompa funebris de funerales importantes que ayudan a la teatralidad y dramatización del funeral como la música, los mimos, las máscaras, las imagines de los antepasados del difunto, la imagen del propio difunto, el lecho fúnebre, etc.

${ }^{46}$ Dión Casio (Hist.56.46) dice que ese senador y expretor fue Numerio Ático, y que éste hizo tal juramento tras pagarle Livia un millón de sestercios.
} 
$\operatorname{cio}^{47}$. Aunque para nosotros la fórmula usada por el biógrafo latino (nec defuit) es de interpretación dudosa en cuanto a la intención de éste ${ }^{48}$.

Y, como último momento del funeral, Suetonio nos dice quiénes recogieron las cenizas de Augusto (primores equestris ordinis) y dónde las depositaron (ac Mausoleo condiderunt). Se deduce, pues, que la propuesta de algunos senadores, referida antes por él, a saber, la de que tal acción la llevaron a cabo los sacerdotes de los principales colegios sacerdotales no fue aprobada en el Senado ${ }^{49}$. Es probable que esta precisión, que realza de nuevo el papel de los equites en el funeral de Augusto, obedezca a aquella tendencia filo-ecuestre que antes señalábamos para Suetonio. Además hay que destacar que, a pesar de su prisa, Suetonio no deja de señalar que esos equites iban tunicati et discincti pedibusqe nudis, es decir, vestían únicamente la túnica, sin cinturón y con los pies descalzos, señal de duelo que no es mencionada en ningún otro momento como propia de los funerales. Rasgo este propio del biógrafo que ama el detalle realista y la anécdota, en este caso reveladora de la teatralización del gran luctus que embargaba a Roma. Por otra parte la selección y presentación de los hechos comentados de este apartado parece estar guiada, fundamentalmente, por las mismas dos ideas que invocábamos para los datos del Apartado II.

Al relato del funeral le sigue, cerrándolo, una muy rápida pero preciosa noticia (Apdo. VI) que Suetonio nos ofrece sobre el Mausoleo de Augusto. Lamentablemente en ella no se describe el monumento pero sí se señala el lugar y, lo que es más valioso, la fecha de su construcción. Ello lo entendemos como fruto de sus intereses de erudito y anticuario. Pero a la vez aparece el biógrafo pues, en una hábil unión sintáctica y conceptual con lo anterior, Suetonio concluye el relato diciendo que en la misma fecha de su construcción (sexto suo consulatu) Augusto ya había donado al pueblo los paseos y jardines que rodeaban el Mausoleo. Aflora en este dato la magnanimitas de Augusto y no deja de ser verosímil que al señalar este hecho Suetonio pretenda exaltar la figura de Augusto a la vez que consigna algo que juzga importante para la historia de la $V r b s^{50}$.

En cambio, de casi todos los detalles citados por Suetonio en los Apartados II, III y VI prescinde el historiador Tácito. Éste con seguridad piensa en ellos (o, al menos, en algunos de ellos) cuando al finalizar su relato (Ann.10.8) nos dice: ceterum sepultura more perfecta, es decir, finalizado su entierro según la costumbre. Sin duda, son detalles que, dado su concepto de que sólo lo importante (res inlustres) es digno

\footnotetext{
${ }^{47}$ Fundamental para la cuestión de la ‘ascensión’ del que será divinizado es Weinstock (1971, pp.356 y ss.), a propósito de César.

${ }^{48}$ Arce (1988, p.126, n.6) cree que con esa fórmula Suetonio insinúa que tal ‘visión’ venía de mucho antes y que no era exclusiva de los funera imperatoria. Pero a nosotros nos parece que el nec defuit suetoniano podría llevar también su carga de irónico escepticismo respecto a la divinización de los emperadores; escepticismo que ya señaló Grimal (1973) en su edición de las Vidas de Suetonio.

49 La causa de ello probablemente radicará en la intención de preservar a los sacerdotes de la contaminación que suponía su contacto con un cadáver (Fraschetti 1990, p.73).

${ }^{50}$ No olvidemos, además, que la noticia sobre la tumba no era ajena a la tradición biográfica. Sobre esta cuestión puede verse Giner 1983, pp.229-246.
} 
de la historia ${ }^{51}$, excluye, seguramente por parecerle innecesarios y en principio no propios de este género ${ }^{52}$. Y además tenemos la velocitas que le apremia. Tan solo en uno de los datos atrás invocados coincide Tácito con Suetonio: aquél en que se refiere (Apdo. II, $\mathrm{n}^{\circ} 1$ ) a que el cortejo fúnebre saliera hacia el Campo de Marte por la puerta del triunfo (porta triumphali). Lo cual no es casual pues ello enlaza con la verosímil contaminación ideológica que hubo entre los funerales de los emperadores, su apoteosis y la celebración del triunfo militar ${ }^{53}$, es decir, tal hecho para Tácito encerraría un claro significado político. Y ese interés por el aspecto político del funeral es lo que explica que el autor de los Anales, aunque se dispone a ser muy selectivo (recuérdese el ex quis [honoribus] qui maxime insignes visi de antes) nos aporta detalles, datos y aspectos ignorados por Suetonio, que enlazan con la vertiente política de Augusto: son los que en nuestro cuadro sinóptico llevan los números 3, 4, 5, 6, 7, 13, 14 y 15 del Apartado II. De ellos, en los dos primeros Tácito se fija en la especie de estandartes que, a propuesta de los senadores Galo Asinio y Lucio Arruntio respectivamente, se llevan en el cortejo fúnebre con los legum latarum tituli $\left(\mathrm{n}^{\circ}\right.$ $3)$ y los victarum ab eo gentium vocabula $\left(n^{\circ} 4\right)$. Seguramente Tácito se fija en este detalle porque quiere ver en el primer caso el símbolo de la política interior ${ }^{54}$; y en el segundo caso, a la vez que el símbolo de la política exterior de $\operatorname{Augusto}^{55}$, la idea de triunfo militar a la que antes nos referíamos ${ }^{56}$. Y queremos remarcar que mientras que Suetonio nos da de forma anónima las propuestas de los senadores, Tácito, haciendo gala en este caso de una información muy precisa ${ }^{57}$, nos concreta el nombre

\footnotetext{
${ }^{51}$ Filosofía de Tácito que podemos ver expresada, entre otros, en estos dos pasajes: Ann.13.31.1: nisi cui libeat laudandis fundamentis et trabibus, quis molem amphitheatri apud Campum Martis Caesar exstruxerat, volumina implere, cum ex dignitate populi Romani repertum sit res inlustres annalibus, talia diurnis actis mandare. Y Ann.3.65: exequi sententias haud institui nisi insignis aut per honestum aut notabili dedecore quod praecipuum munus annalium reor ne virtutes sileantur utque pravis dictis factisque ex posteritate et infamia metus sit.

52 Tal actitud se ve refrendada en Tácito en multitud de ocasiones. Invoquemos ahora, por el paralelismo con la noticia que nos ocupa, lo que éste hace al dar cuenta de las honras póstumas decretadas por el Senado para Germánico (Ann.2.83): frente a los veintisiete honores decretados por el Senado, que recoge la Tabula Siarensis, Tácito solo nos habla de doce. Para este último dato, $c f$. González (2002, p.13).

53 Séneca (Dial.6 cap.3.1) se refiere al funus imperatorium como funus simillimum triumpho. Sobre este debatido aspecto del funus imperatorium puede verse Brelich (1938, pp.189-193); Richard (1978, pp.11221125); Arce (1988, pp.35ss).

${ }^{54}$ Alusión a las conocidas leyes: Lex de adulteriis; Lex Julia de maritandis ordinibus; Lex Furia Caninia; Lex de senatu; Lex de magistratibus; Lex de ambitu, etc. Precisamente Suetonio (Aug.34) enumera varias de estas leyes al dar cuenta de la reformas sociales de Augusto.

55 Recuérdese que Augusto puso fin a la conquista de Hispania, del Nórico, de lo que después se llamaría Panonia y de la Mesia superior. Cf. Suetonio, Aug.21: domuit (Augustus) partim ductu partim auspiciis suis Cantabriam, Aquitaniam, Pannoniam, Delmatiam cum Illyrico omni, item Raetiam et Vindelicos ac Salassos, gentes inalpinas.

${ }^{56}$ Queremos recordar a este respecto cómo el senatus consultum de honoribus Germanici decernendis (recogido en la Tabula Siarensis) se refiere también a que el arco que se ha de construir en honor de Germánico, tras su muerte, debe estar adornado con relieves dorados de los pueblos vencidos (cum signis deuictarum gentium inauratis). Cf. texto, traducción y comentario de la Tabula Siarensis en González (2002, pp.299ss.; el texto citado en p.300).

${ }^{57} \mathrm{Ni}$ Suetonio ni Dión Casio concretan los nombres de los senadores que hacen las propuestas: ¿podemos deducir de ello que en esta ocasión tuvo Tácito como fuente no un historiador anterior sino los Acta Senatus?
} 
de varios protagonistas como son los atrás citados Asinio Galo, Lucio Arruntio y Valerio Messala ${ }^{58}$.

También lleno de intención, y de mayor calado, es lo señalado por Tácito en los $\mathrm{n}^{\text {os }} 5-7$ y 13,14 y 15 de ese Apartado II. En ellos el historiador introduce en la discusión del Senado sobre las honras fúnebres de Augusto un nuevo y esencial actor, Tiberio. En primer lugar a propósito de una extraña propuesta, la hecha por Messala $\left(\mathrm{n}^{\mathrm{os}} 5-7\right)$, la cual parece extemporánea a primera vista por no ir referida directamente a un honor relativo a Augusto. El juramento aquí aludido (renovandum per annos sacramentum in nomen Tiberii) es el que implicaba el sacramentum de los soldados y el juramento de lealtad de los civiles al nuevo emperador y tenía lugar a poco de conocerse la muerte del predecesor ${ }^{59}$, aunque no dejaría de tener un carácter provisional (Koestermann 1963, p.86). De tal juramento hacia Tiberio Tácito nos había dado ya cuenta en el capítulo anterior ${ }^{60}$. Entonces lo que ahora propone Messala es que ese juramento hacia Tiberio se renueve cada año ${ }^{61}$. Pero ¿qué hace una propuesta como ésta en medio de las propuestas que atañen al funeral de Augusto? Que la propuesta es extemporánea ${ }^{62}$ se ve también, en mi opinión, en algunos detalles lingüísticos, como es el uso del léxico aquí empleado y en el uso de los tiempos verbales. Para las propuestas de Asinio Galo y de Lucio Arruntio, Tácito utiliza el término técnico censuere, es decir, el que significa hacer una propuesta formal en el Senado (Hellegouarch'c 1963, pp.118-119); por el contrario, ésta de Valerio Messala se introduce por un término común y neutro. Además los verbos del texto en cuestión están en perfecto (censuere), el tiempo por excelencia de la narración, o en presente histórico (conclamant); pero el de la propuesta de Messala es imperfecto,

La crítica de hace algunos decenios era más bien proclive a negar que Tácito tuviera los Acta Senatus como fuente importante en sus obras. Nosotros pensamos que esa actitud posiblemente se debe a la influencia de la conclusión general a la que llegó Fabia (1967, p.319): «En somme, directement les Annales ne doivent à peu prés rien aux Acta Senatus». Sin embargo, Syme (1977, p.235, n. 14 y p.236) es menos categórico en el rechazo del uso de los Acta Senatus por Tácito. Además hoy disponemos de nuevos datos que avalan dicho uso. A esta conclusión lleva, por ej., el estudio comparativo del Senatus Consultum de Pisone Patre, publicado en 1996 a partir de las seis copias epigráficas encontradas en la Bética y el capítulo que Tácito (Ann.2.83) dedica a las honras fúnebres de Gérmanico. $C f$. para esta cuestión González (2002, p.14).

${ }^{58}$ Dado lo selectivo que, en nombres y cosas, se muestra Tácito podemos deducir tanto que estos senadores fueron quienes llevaron a cabo las intervenciones más importantes como que ellos eran oradores de peso en el Senado. Cf. Syme (1958, p.322) y R.E., sub vv.

59 Sobre esta cuestión interesa, entre otros trabajos, Le Gall, J. (1990).

${ }^{60}$ Ann.1.7: Sex. Pompeius et Sex. Appuleius consules primi in verba Tiberii Caesaris iuravere, aputque eos Seius Strabo et C. Turranius..., mox senatus et populus. Parece que el juramento mencionado aquí no es el mismo que el aludido en Tac., Ann.1.72: (Tiberius) neque in acta sua iurari, quamquam censente senatu, permissit... Cf. Fourneaux (1896, pp.189-193) y Goodyear (1981, pp.139-140).

${ }^{61}$ Del posterior silencio de Tácito, así como de las demás fuentes sobre la renovación anual de este juramento se puede deducir que Tiberio rechazó esta propuesta, la cual se puso en práctica en el reinado de Calígula y continuó después (Goodyear 1981, p.148).

${ }^{62}$ A tenor de lo que el propio Tácito $(A n n .2 .38)$ nos dice no debió ser infrecuente que un senador se saliera en su intervención de las cuestiones del orden del día, caso que se estaría dando aquí, en la intervención de Messala. Pero la extemporaneidad en este caso es mayor si no olvidamos las palabras con que Tácito comienza este capítulo 8: nihil primo senatus die agi passus est nisi de supremis Augusti... 
lo que contribuye a la idea de que ello es algo ajeno a lo que se está tratando, y que inesperadamente alguien introduce en el debate. Dado el ambiente y momento en que se expone, es como si Messala, sorprendiendo y de forma espontánea e imprevista (sponte dixisse repondit Messala)), se saliera del guión esperado, proponiendo ese juramento a Tiberio. Por eso Tiberio, parte afectada y que a la vez domina la situación, siente la necesidad de que Messala aclare a los senadores si tal propuesta la hacía porque él se lo hubiera pedido. Seguramente Tácito tenía in mente aquello de excusatio non petita accusatio manifesta al ofrecernos esta reacción de Tiberio, un caso más del innuendo. Ello, además, le dará pie a realizar una intervención auctorial, ea sola species adulandi supererat, para exponer una crítica que se retrotrae a lo dicho en el cap.7 y que, de algún modo, sobrevuela en todos estos capítulos, la servidumbre de Roma entera ${ }^{63}$, comenzando por el Senado, hacia los nuevos detentadores del poder, es decir, del príncipe de turno ${ }^{64}$.

Y, en segundo lugar, aparece de nuevo Tiberio, a propósito de la propuesta de los senadores que unánimemente (conclamant) piden ser ellos los que, a hombros, lleven el cadáver de Augusto hasta la pira, en el campo de Marte. En relación a ella Tiberio se nos muestra dominando la situación (adroganti moderatione) y, posiblemente ${ }^{65}$, negando la petición de un honor que le parece excesivo. Además, en la misma línea de frenar lo que cree excesos (nimis studiis) en la exaltación de Augusto y de modo previsorio teniendo en cuenta lo ocurrido en el funeral de César (quondam funus divi Iulii turbassent), promulga un decreto advirtiendo al «pueblo» que la incineración de Augusto debe hacerse no en el Foro sino en el Campo de Marte, que era el lugar elegido. Tácito ahora deja explícito que el sujeto del edicto monuit es Tiberio (Caesar) y no el Senado dando siempre la imagen, sutilmente, de que en ese interregno legal ${ }^{66}$ Tiberio se comporta ya como princeps. De estos hechos, importantes bajo el punto de vista político para la Roma de aquellos días, no se ocupa Suetonio.

Por su parte, en el por nosotros llamado Apdo. III (celebración de las exequias) Tácito se refiere solo al hecho de que el día del funeral, precisamente para garantizar el orden al que se aludía antes, Tiberio hiciera salir a las calles la fuerza militar. Tácito realiza una irónica crítica de tal medida haciendo ver lo ridícula que resulta la comparación que hacía Tiberio, para justificar tal medida, entre dos momentos tan

${ }^{63}$ Incluso aunque tal propuesta tuviera lugar realmente, solo de Tácito depende la selección y ubicación de los datos. De otro lado, queremos recordar también que quien hace la propuesta del sacramentum renovandum per annos es Valerio Messala, el mismo importante senador que en la Vida de Augusto suetoniana (Aug.58) encontramos proponiendo a Augusto, ahora en nombre de los senadores, el título de pater patriae: is (Messala), mandantibus cunctis... senatus te consentiens cum populo Romano consalutat patriae patrem.

${ }^{64}$ Cf. Ann. 1.7: at Romae ruere in servitium consules, patres, eques quanto quis inlustrior tanto magis falsi ac festinantes vultuque composito.

${ }^{65} \mathrm{Cf}$. nuestro apéndice II acerca de la interpretación de la frase remisit Caesar adroganti moderatione.

66 Tiberio convocó al Senado en base a su tribunicia potestas según había dicho ya (Ann.7.2): ne edictum quidem, quo patres in curiam vocabat, nisi tribuniciae potestis praescriptione posuit sub Augusto acceptae; lo cual corrobora Suetonio en Tib.23.1: iure autem tribuniciae potestatis coacto senatu incohataque adlocutione derepente uelut impar dolori congemuit. 
diferentes como eran el del funeral de Augusto y el del asesinato y funeral de César ${ }^{67}$. Seguramente nuestro historiador, con una presentación personal y parcial de los he$\operatorname{chos}^{68}$, lo hace también con la intención de hacer patente que Tiberio tiene de su lado aquella fuerza militar y que la discusión de las cosas en el Senado bajo un aparente plano de igualdad es mera fachada sin que haya que descartar la intención de sugerir que el proceso de la translatio imperii y tal vez parcialmente algunos hechos de las mismas honras fúnebres no carecerían de una cierta coacción en un sentido o en otro. Y de paso recuerda al lector que los días del asesinato de César todavía tenían la dignidad de un cierto rechazo de la tiranía (seruitium) y de una cierta esperanza, frustrada por supuesto, de recuperar la libertad: diem illum crudi adhuc seruitii et libertatis improspere repetitae. Eso sí, siguiendo un procedimiento muy querido por él (uso de las opiniones de los demás) esta crítica es indirecta pues la pone en boca de los romanos que asisten y observan la sucesión de los hechos del funeral (multum inridentibus qui).

Y, sobre todo, avanzando en el relato, tenemos en Tácito el Apartado IV de nuestro esquema, con los caps. 9 y 10, sin correlato en Suetonio, dedicados a los comentarios que los romanos asistentes al funeral de Augusto hacen sobre el muerto. Nosotros creemos que, contra lo que puede sugerir una primera impresión, hay que entender estos dos capítulos como parte de la unidad temática "el funeral de Augusto". Y ello, para empezar, por una razón de tipo formal: la que suponen las fórmulas con que Tácito abre y cierra el contenido de esos dos capítulos. En efecto, su apertura se hace con un adverbio pronominal: ut sepultura eius quieta foret (Ann.8, final) más: multus hinc ipso de Augusto sermo (Ann.9, comienzo), que viene a engarzar los comentarios sobre Augusto con la ceremonia del funeral a modo de consecuencia. Y es que el hecho de que se viene hablando justo antes, es decir, las honras fúnebres que contemplan (die funeris..., multum inridentibus..., nunc... ut sepultura eius quieta foret) es lo que provoca como cosa natural que los romanos comenten sobre la figura de Augusto. Y, puesto que éste ha sido el prócer que durante tanto tiempo marcó su vida política, Tácito hace parecer lógico que sus comentarios recaigan sobre esta faceta. Por su parte, la frase ipso de Augusto nos revela que el autor cambia de plano pero sin salir de la misma escena: se deja de hablar de las medidas que otros toman respecto a la celebración del funeral para referirse a lo que los romanos decían del propio protagonista pasivo del mismo: ipso de Augusto. Y, por el lado contrario, es decir, a la hora de cerrar esos comentarios sobre el Augusto que ya está enterrado y será divinizado, Tácito utiliza una fórmula que viene a encerrar todo lo que ha dicho a lo largo de esos dos capítulos dentro del relato del funeral: ceterum, sepultura more perfecta, tem-

\footnotetext{
${ }^{67}$ Ambos bien descritos por Suetonio, Iul.82-89 y por Apiano, Hist.2.117-149. No es del todo claro a qué día concreto se refiere el diem illum (crudi adhuc seruitii et libertatis improspere repetitae), si al día del funeral de César o al día en que éste fue asesinado. Woodman (2002, pp.629-632) hace el estado de la cuestión de este detalle y defiende como más verosímil que el diem illum se refiere al día del asesinato de César.

${ }^{68} \mathrm{El}$ hecho de sacar el ejército a la calle, para garantizar el orden, no era tan excepcional, si tenemos en cuenta que ello había sucedido ya en el funeral de Sila y, en tiempos más recientes y menos agitados, en los funerales de Cayo César y de Druso II. Además ello enlazaba con el aspecto triunfal del funus imperatorium.
} 
plum et caelestes religiones decernuntur. Hasta llegar a estas últimas frases al lector no se le dice que el funeral y enterramiento (sepultura) haya acabado pues, aunque el autor no se haya detenido en las ceremonias, ni en otros hechos, como el iustitium, vinculados a los funerales, se da a entender que éstas se habían ido desarrollando según el uso habitual (more) del funus publicum; pero, ahora sí, se da por finalizado el funeral (sepultura perfecta) ${ }^{69}$. En estos dos capítulos el historiador romano nos proporcionaría, pues, de forma concentrada y disfrazada bajo los comentarios de los romanos, el juicio político sobre el emperador ${ }^{70}$. Juicio que, tanto por el tema que trata como por la forma en que lo hace, representa uno de los momentos cumbres de los Anales de Tácito, lo que explica que haya sido objeto de múltiples estudios ${ }^{71}$.

Una vez establecido esto, analicemos ahora las técnicas y recursos literarios con que el autor compone, dentro de la unidad temática que es el funeral, la subunidad del juicio político sobre Augusto. Más tarde, al hacer un balance final comparativo entre el texto de Suetonio y el de Tácito, versaremos sobre qué razones pudieron llevar a éste a realizar una síntesis valorativa sobre la figura de Augusto justo en el relato del funeral.

\footnotetext{
${ }^{69}$ No se olvide que tratamos fundamentalmente de literatura, en concreto de literatura del género 'historia'. Por ello hablamos aquí de una unidad temática, la cual sin embargo abarca hechos diversos y discontinuos en la realidad histórica. En efecto, lo que en estos momentos Tácito nos narra bien ensamblado y creando la ilusión de unidad e ininterrumpida continuidad (recuérdese la función del hinc invocado antes) no responde del todo a la realidad histórica de los hechos aludidos. En efecto, la muerte de Augusto tuvo lugar en Nola el 19 de agosto del 14 d. C. Su cadáver llegaría a Roma probablemente 10 días más tarde. Al día siguiente de su entrada en la ciudad tendría lugar una primera sesión del Senado, convocada por Tiberio, la cual versaría sobre la organización de los funerales (de supremis Augusti); tal vez a continuación de esta sesión, o tal vez a continuación del entierro en el Mausoleo de los restos de Augusto, tendría lugar el iustitium. De este modo el funus propiamente dicho tendría lugar entre el 5 y el 10 de septiembre. Y sólo en otra sesión del Senado, el 17 de septiembre, tuvo lugar la sesión de la consecratio, en que Augusto fue declarado divus, es decir, la sesión aludida por Tácito cuando, al finalizar su relato del funeral, dice: ceterum sepultura more perfecta, templum et caelestes religiones decernuntur. Como se ve, Tácito prescinde de muchos de los hechos que conocemos sobre este asunto (unos por Suetonio, otros por Dión Casio, otros por las inscripciones); incluso prescinde de una reconstrucción que, como la anteriormente expuesta, se atenga tan solo a los hechos más elementales. Y ni qué decir tiene que el devenir político de esos días fue más rico y complejo que lo indicado en la anterior reconstrucción (para la reconstrucción de la secuencia histórica expuesta he seguido a Grenade (1961,pp.416 y ss.), en la cual ni se habla del número de sesiones del Senado que pudieran haber tenido lugar entre la llegada del cadáver y la consecratio ni del dies imperii de Tiberio o, lo que es lo mismo, la duración del iustitium, del interregno, etc. Devenir que es francamente difícil de reconstruir de modo detallado en su secuencia cronológica. Tácito, principal fuente para los hechos que nos ocupan, procede aquí más como escritor y artista que como historiador, razón por la cual prescinde en gran manera de la explicitación de la cronología de los hechos aludidos. Ello obliga al estudioso moderno a meras conjeturas realizadas a partir de ciertos elementos léxicos o estilísticos o de la comparación con elementos paralelos de otros momentos. Por supuesto, todo ello ha sido discutido en la pertinente bibliografía, de la cual solo quiero recordar, como más imprescindibles, además del citado Grenade, Wellesley (1967, pp.23-30); Hohl (1993, pp.105-115); Pippidi (1965, pp.125132); Koestermann (1961, pp.330-335); Beranger (1953); Goodyear (1972, pp.169-171).

${ }^{70}$ Sobre hasta qué punto el juicio sobre Augusto expresado en los capítulos 9 y 10 representa la opinión real de los romanos a la muerte de Augusto o es fundamentalmente el juicio que éste le merecía a Tácito véanse las páginas siguientes, especialmente sus notas.

71 Muchos de ellos se citarán en las páginas siguientes a medida que su uso se imponga o sea conveniente. Ahora solamente deseo adelantar la cita de uno de ellos: Velaza (1993, pp.335-356).
} 
El texto de estos capítulos de los Anales, elaborado con una técnica más descriptiva que narrativa ${ }^{72}$, goza de una compleja y lograda elaboración artística y retórica. Primeramente Tácito contrapone ${ }^{73}$ los comentarios de la mayoría (plerique) a la de los prudentes o avisados en los temas de la res publica, y que, por oposición implícita, son pauci $i^{74}$. Nuestro autor, buen psicólogo ${ }^{75}$ e intérprete avisado de la historia de Roma, lógicamente apenas se detiene sobre los primeros ${ }^{76}$, los cuales versan sobre cosas llamativas pero banales (vana mirantibus) ${ }^{77}$, aunque sin duda su presencia y sus comentarios ayudan a completar el retrato de la atmósfera social del momento en que muere Augusto. Pero lo que de veras le importa a Tácito es la opinión y valoración que de Augusto se expresa en los comentarios de los prudentes. Pues bien, Tácito, hombre de vocación oratoria y de gran preparación para ella (Syme1958, p.66; Aubrion 1991, p.2597-2688 y passim), sin olvidar que también escribe para un público culto que desde la escuela conoce bien las técnicas de la oratoria, expresa las opiniones de aquellos con el artificio oratorio de la controuersia in utranque partem ${ }^{78}$ : At apud prudentis vita eius varie extollebatur arguebaturve. Este planteamiento le lleva a dedicar la segunda parte del cap. 9 a recordar, de forma muy rápida, los principales hitos de la vida política de Augusto, tal como los veían la parte de los prudentes que le era favorable (extollebatur). Y la elección de tales hitos obedece a criterios de base ética y política: fundamentalmente la pietas erga parentem y la necessitudo reipublicae (Ferrero1946, pp.62-63). Después simétrica y, a la vez, antitéticamente ${ }^{79}$, a lo largo de un amplio capítulo, el 10, Tácito nos muestra un cuadro panorámico de la vida política de Augusto, recogiendo la interpretación in malam partem (arguebatur; dicebatur contra) no solo de aquellos hechos que, con una valoración positiva, se ofrecían en el capítulo anterior sino también de unos cuantos más que, con toda intención, se añaden ahora, incluyendo algunos relativos al ámbito personal y familiar (nec domesticis abstinebatur). La idea de la doblez y la maquinación de Augusto, movido siempre por la cupido dominandi, proporciona el hilo conductor en la elección y secuenciación de los hechos de este capítulo que, en general, siguen un orden cronológico.

${ }^{72}$ En la segunda parte del cap. 8 es narrativa, en los caps. 9 y 10 fundamentalmente descriptiva.

${ }^{73}$ Contraposición que el autor quiere hacer de modo claro y fuerte mediante el uso del at que, relegando las cosas de los poco avisados (vana mirantibus), deja paso al juicio sobre Augusto.

${ }^{74}$ Puede que por debajo de la oposición plerique (=vana mirantibus) frente a prudentes (=pauci, implícito) se halle la oposición entre mali y boni, que se arrastraba desde atrás en el mundo de la retórica, y que recoge, por ej., Quintiliano (Inst.5.10.17). Cf. a este respecto Aubrion (1991, p.2628).

${ }^{75}$ Una acertada, aunque breve y en parte obvia, matización a lo que se debe entender por 'psicólogo' hablando de Tácito (capacidad de observación y buena intuición frente a los más complejos conceptos y métodos modernos) puede verse en Alexander (1952, pp.326-328).

${ }^{76}$ Para una primera aproximación a la (negativa) opinión que Tácito tiene del uulgus, aquí implícito en plerique, pueden verse Newbald (1976, pp.85-92) y Aubrion (1991, pp.2617-2618).

${ }^{77}$ En concreto, cinco detalles, entre ellos, el recordatorio del imponente número de veces que Augusto detentó las más altas magistraturas, despachando el autor otros honores con el genérico aliaque honorum multiplicata aut nova.

${ }^{78}$ Para este concepto, $c f$. Cicerón, De Orat.3.21.80; Aubrion (1991, p.2609) señala su uso aquí.

${ }^{79} \mathrm{El}$ analizar y juzgar los hechos y las personas según biparticiones, procedimiento de valoración cómodo y presente en la Retórica, es algo practicado con frecuencia por Tácito (Bardon 1953, pp.25-28). 
Por tanto, la presentación que Tácito ofrece al lector de la figura de Augusto está hecha, aparentemente, de forma neutra y equilibrada e imparcial (sine ira et studio) ya que recoge, contraponiéndolas antitéticamente, las distintas opiniones que, según él, los romanos tenían y manifestaban sobre Augusto, mostrando así la división de éstos a la hora de juzgar al fundador del Principado ${ }^{80}$. Bien examinadas, sin embargo, las cosas no son así. En efecto, el espacio que Tácito dedica a la parte negativa (arguebatur) es casi dos veces mayor que el dedicado a la parte positiva. Y mediante esa mayor acumulación de hechos, acusaciones, a las que aluden los rumores, mediante la mejor explicitación y explicación que reciben los hechos negativos que los positivos, y gracias también a un estratégico uso de algunos elementos lingüísticos, que después señalaremos, Tácito logra, sin duda, que en la mente del lector pese más la imagen negativa de Augusto.

Como vemos, Tácito nos ofrece el balance del Augusto político mediante el ya citado recurso a las opiniones de la gente o rumores ${ }^{81}$, introduciendo todo el texto con aquella frase de multus hinc ipso de Augusto sermo, que implica un rumor complejo (multus sermo) o, mejor, una suma de rumores, bien ensamblados, eso sí, con la lógica y los hilos conductores a los que antes hicimos referencia. Por ello los verbos que dan entrada a las opiniones sobre Augusto, todos en imperfecto, o son usados de modo impersonal (extollebatur, arguebatur, dicebatur, nec abstinebatur) o el sujeto de los mismos es colectivo (plerique, prudentes); y, lógicamente, la mayor parte del texto está construida en estilo indirecto. ¿Qué pudo mover a Tácito a utilizar este recurso del rumor complejo ${ }^{82}$ para valorar la figura de Augusto? Sabido es que nuestro autor tiene como uno de los principios que guían su narración el señalar las reacciones del pueblo porque piensa que ello puede dar cuenta del estado de ánimo, es decir, de la opinión pública de los romanos en un momento dado ${ }^{83}$. Pero hay además otras

\footnotetext{
${ }^{80}$ No es nuestro propósito entrar aquí ni en la veracidad de los hechos invocados ni en las fuentes que para ellos usó Tácito, puntos que obviamente han sido tratados también por los estudiosos. Sobre ellos versan, por ej., Haverfield (1912, pp.197-199), el cual demuestra que Tácito conoció y usó las Res Gestae divi Augustii; Lord (1927, pp.121-122), que en un escueto artículo presenta las coincidencias de Tácito con otras fuentes históricas como las Res Gestae diui Augusti, Dión Casio, Suetonio, Cicerón y Séneca; y Urban (1979, pp.5974), autor que profundiza en el uso que Tácito hizo aquí de las Res Gestae del propio Augusto, girando el punto de vista in malan partem a la hora de aludir a los hechos invocados por Augusto. Y también Velaza (1993, pp.346-353) versa sobre el uso que hace Tácito de las Res Gestae, sobre un cierto paralelismo con Dión Casio y sobre la posibilidad de una fuente común entre ambos autores. Por su parte, Lenchantin (1938, pp.337-345), una vez asumido que las acusaciones a Augusto del cap.10 representan el punto de vista de Tácito, se detiene en señalar la falsedad e injusticia de algunas de tales acusaciones.

${ }^{81}$ Una mirada general, aunque sintética, sobre el importante papel que el uso de los rumores supone en el modo de historiar de Tácito puede verse en Hinojo - Lorenzo - Moreno (1979, pp. 232-233).

${ }^{82}$ Sermo es la expresión oral de la fama, es decir, en muchos casos los sermones vienen a equivaler a los rumores.

${ }^{83}$ Sobre el uso que en Historias y Anales hace Tácito de la voz de la gente, de los rumores, de la opinión pública existe un viejo debate que pretende aclarar tanto su función como si tales voces o rumores responden a una realidad histórica o es mero artificio retórico. La mayoría de los autores (entre ellos, Nipperdey-Andresen, Boissier, Fourneaux, Marsh) admiten su realidad histórica. Por contra Fabia, Pippidi y otros son de la opinión de que, salvo en casos concretos, estamos ante un recurso artístico. De la abundante bibliografía ya existente sobre tales cuestiones solo mencionaremos aquí: Ferrero (1946, pp.50-86) y Shatzman (1974, pp.549-578).
} 
razones. Tal modo de proceder proporciona emoción al relato; en este caso concreto se podría decir que Tácito no sólo da cuenta de los funerales de Augusto sino que, además, de algún modo hace revivir en el lector los sentimientos, contradictorios, que sobre el protagonista pasivo de los mismos embargaban a los romanos que los observaban. Y seguramente Tácito pensaría también que ganaba en credibilidad si escondía a primera vista su subjetividad bajo la capa de las opiniones de otros ${ }^{84}$. Todo ello pesaría en nuestro autor a la hora de elegir esta forma de presentarnos la figura de Augusto.

De otro lado, Tácito utiliza en la elaboración de estos dos capítulos otro recurso artístico muy querido para él, a saber, el innuendo ${ }^{85}$, es decir, el hecho de usar la alusión rápida y la insinuación negativa frente a la declaración y acusación abierta y directa; incluye también este recurso la oferta de la doble explicación de un hecho en la cual la opción negativa es puesta en ventaja mediante sutiles mecanismos lingüísticos y retóricos ${ }^{86}$. Así, por ej., en estos dos capítulos de Tácito, 9 y 10, se observa un comportamiento muy diferente a este respecto por parte del autor. En efecto, en el cap. 9, el de la presentación positiva de los hechos de Augusto, nuestro autor despacha con rapidez, de forma un tanto desvaída y con léxico poco expresivo ${ }^{87}$, una asunción del poder por Augusto que en principio parece justificada por las circunstancias: postquam hic (Lepidus) socordia senuerit, ille (Antonius) per libidines

Nosotros creemos, con Ferrero, que una perspectiva aclaradora es la de diferenciar el sustrato histórico, que en la mayor parte de los casos podían tener los rumores, de su formulación artística concreta.

${ }^{84}$ Se ha discutido si la verdadera opinión de Tácito sobre Augusto es o no lo que nuestro autor dice en el cap. 10. En nuestra opinión, la respuesta no es fácil ni puede ser contundente por la ausencia de marcas lingüísticas que, como el uso de la primera persona o de adverbios como nunc, etc, implicarían directamente al autor. La opinión mayoritaria es que sí, que el verdadero juicio de Tácito acerca de Augusto es el que se deriva de lo que dice (estamos viendo de qué modo) en ese capítulo 10. Pero en contra de esta tesis mayoritaria no faltan voces importantes como la de Aubrion (1991, p.2607), la de Cousin (1951, pp.239-241) o Shotter (1967, pp.171-174), el cual, basándose en que la mayor extensión de ese cap.10 no es un hecho significativo, cree que Tácito no toma partido claro entre los apologistas y los detractores de Augusto. Nosotros pensamos que, como venimos viendo, la mayor extensión del texto dedicado a las acusaciones no es un dato aislado sino que va compañado de otros hechos lingüísticos y retóricos, todos ellos convergentes y que revelan que el autor prima esa opinión negativa, a la cual quiere dar más relieve. Codoñer (1999, pp.87 y ss.), señala algunos de esos hechos lingüístico-estilísticos que pueden reforzar la idea de que Tácito se implica más en la idea negativa y crítica hacia Augusto. Más precisamente señala la introducción de la 'sentencia' quamquam fas sit privata odia publicis utilitatibus remittere y la inserción en la última parte del cap.10 (etenim...iecerat) del estilo directo, el cual revelaría la complicidad de Tácito con lo que se dice bajo esa forma sintáctica, forma que no deja de contrastar con el uso exclusivo del estilo indirecto (rumores) para recoger las opiniones favorables a Augusto (cap.9, segunda parte).

85 Para el innuendo en Tácito pueden verse, como importantes, entre otros, Ryberg (1942, pp.383-404); Daitz (1960, pp.46-47); Develin (1983, pp.64-95) y Whitehead (1979, pp.475-495).

${ }^{86}$ Entre los cuales cuenta un peculiar uso de la coordinación disyuntiva marcada por la partícula sive (seu) cuyo uso estudió ya Wölfflin (1867) y del cual uso dijo: «Tacitus, quidquid hoc modo (scil. 'enuntiato disiunctivo') exponit, duas pluresve causas, priorem scilicet naturalem bonamque, ultimam vero subdolam quin etiam pravam affert» (apud Waele 1930, p.311).

${ }^{87}$ Los verbos están en pasiva y son de color (tono) neutro o débil: parari, actum, haberi, concesisse, fuisse, constitutam, sin olvidar que justo en el capítulo en que se recuerdan sus logros Augusto aparece como sujeto solo en tres ocasiones (Miller 1969, p.103). 
pessum datus sit non aliud discordantis patriae remedium fuisse quam $<$ ut $>$ ab uno regeretur. Non regno tamen neque dictatura sed principis nomine constitutam rem publicam. Por contra en el cap. 10, el de la presentación negativa de aquellos hechos, las alusiones a cómo Augusto se hizo con el poder están hechas con un léxico revelador en el cual los verbos de los que Augusto es sujeto giran todos en torno a la idea de que el princeps arrebató poderes, militares y civiles, ilegalmente: invaserit, abstulerat, occupavisse, sin olvidar que los verbos en pasiva ${ }^{88}$, que señalan a sujetos individuales o colectivos engañados o extorsionados, tienen a Augusto como sujeto agente, expreso o tácito. Además la fuerza de los rumores contra Augusto sumados por Tácito en el cap.10 se ve aumentada por la presencia en él de un léxico de mayor vigor y fuerza ${ }^{89}$. Por su parte, el modo en que Tácito nos presenta las posibles causas de las muertes de los cónsules Hirtio y Pansa ilustran bien ese otro recurso del innuendo, que, según dijimos, es la oferta de una doble explicación de un hecho en que la parte más negativa y maliciosa queda sutil e indirectamente puesta en ventaja $^{90}$. Y en el uso del innuendo en este cap.10 habrá que inscribir igualmente la extraordinaria abundancia de términos lingüísticos que oponen a la realidad de los hechos la apariencia con que Augusto quiso dotarlos: obtentui (sumpta); simulatam gratiam; imagine (pacis); specie (amicitiae). Es el modo subliminal e indirecto de llevar a la mente del lector la imagen de un Augusto hipócrita y lleno de doblez en su acción política ${ }^{91}$.

Y, finalmente (Apdo. V), Tácito concluye la unidad temática que conforma el funeral de Augusto de forma lapidaria y solemne y con la brevitas que caracteriza su pluma: ceterum sepultura more perfecta templum et caelestes religiones decernuntur. Es decir, por lo demás, Augusto, finalizado su funeral, fue divinizado. Recuérdese que la forma sintáctico-estilística de la frase (sepultura more perfecta templum et caelestes religiones decernuntur) literariamente ${ }^{92}$ ensambla de algún modo la noticia

\footnotetext{
${ }^{88}$ Paratum ab adulescente privato; concitos...veteranos; corruptas legiones; extortum...consulatum; Pompeium, Lepidum deceptos; Antonium inlectum; interfectos... Varrones.

${ }^{89}$ Como el extortum aplicado al consulado de Augusto, noverca, aplicado a Livia, o las expresiones invito senatu (con un dativo arcaico), machinator Caesar (Augusto), etc. Cf. Miller (1969, p.105).

${ }^{90}$ Caesis Hirtio et Pansa, sive hostis illos seu Pansam venenum vulneri adfusum, sui milites Hirtium et machinator doli Caesar abstulerat. La hábil coordinación disyuntiva (sive...seu) no sirve para enmascarar del todo la preferencia del autor por la segunda explicación, la que hace a Augusto posible culpable de la muerte de estos cónsules pues ella está marcada por una mayor extensión, mayor explicación y una expresión de fuerte colorido y expresividad (machinator doli Caesar). Obsérvese la implicación de reiteración y expresividad que conlleva el sufijo -tor en el sustantivo del sintagma machinator doli. No es, en cambio, significativo a este respecto el que abstulerat esté en indicativo (Whitehead 1979, p.490, n.27).

${ }^{91}$ Lo que, por otra parte, prepara para y engarza con la principal característica con que Tácito dibuja en la primera héxada de los Anales el principado de Tiberio y en general todo el mundo del Principado. Para la idea de que en el mundo imperial para Tácito todo es apariencia, y el reflejo que ello tiene en el léxico de sus Historias y Anales, $c f$. Cousin (1951, pp.238-239) y Pippidi (1938, pp.37ss) e Hinojo (1987, pp.307, 312 y 314).

92 Decimos 'literariamente' porque en la realidad, y Tácito debía saberlo, la consecratio obedece a una decisión del Senado que, muy probablemente, viene después del funus del emperador. Sobre si la consecratio era una declaración del Senado o una ceremonia ha habido una larga discusión que puede verse resumida en Arce (1988, pp.129-131).
} 
de la divinización con el funeral. Tácito, en efecto, y según dijimos ya, comienza por una partícula (ceterum) de enlace que pone fin a los comentarios sobre Augusto, sigue un ablativo absoluto que devuelve la mente a las ceremonias del funus (sepultura more perfecta) y remata con la oración principal en que se enuncia un hecho de gran importancia política y que justamente sigue al funeral: ceterum ...templum et caelestes religiones decernuntur. Vemos, pues, que si Suetonio solo insinuaba este hecho (nec defuit...qui iuraret) indirectamente y como un dato más dentro de las exequias, Tácito, por el contrario, como historiador que gusta de analizar con profundidad los hechos políticos, se fija en la importancia de algo que había supuesto un punto de inflexión en la historia política de Roma ${ }^{93}$.

\section{RAZONES DE LA INDIVIDUALIDAD Y DIFERENCIA DE CADA UNO DE LOS DOS RELATOS EN VIRTUD DEL GÉNERO, DEL PROPÓSITO DE CADA OBRA Y DE LA PERSONALIDAD INTELECTUAL DE CADA UNO DE LOS AUTORES}

De todo lo expuesto se ve que para sendos relatos de un mismo tema el proceder de ambos autores es muy diferente por lo que hace a la selección del material, y a la secuenciación y presentación del mismo así como en la elaboración del relato y su focalización. ¿A qué se puede deber tanta diferencia? Para nosotros la explicación radica, según hemos apuntado ya en diversas ocasiones, de un lado, en la diferencia del género, aunque biografía e historia tenían, y tienen, múltiples interconexiones; $y$, de otro lado, en el propósito que para sendas obras se habían propuesto uno y otro autor, sin olvidar la diferente personalidad intelectual de Suetonio y Tácito.

En efecto, en el caso de Suetonio su relato del funeral de Augusto se inscribe en la escritura de una uita. Ello quiere decir que, por la propia naturaleza del género biográfico, el autor va dibujando para el lector la personalidad, el carácter y el símbolo del protagonista, Augusto, a partir de los hechos de su vida, los cuales nos ofrece progresivamente ya sea per species o rúbricas, que es la técnica literaria más usada por Suetonio, ya sea por orden cronológico ya en una presentación mixta de los mismos pues esa división en absoluto es infranqueable. Y cuando en la composición de la Vita Augusti Suetonio llega a la rúbrica o unidad temática de los funerales de Augusto, que forma parte de la sección ${ }^{94}$ de la muerte del protagonista,

\footnotetext{
93 Es verosímil que una decisión política de tanta trascendencia conllevara sus discusiones. Pero en todo caso creemos que Arce (1988, p.126) no tiene razón al escribir: «Es éste también el caso de Augusto cuya divinización -según el testimonio de Tácito- fue el resultado de una larga y violenta discusión en el seno del órgano ejecutivo de Roma». Y como prueba Arce nos remite a Ann.1.8-9-10. Pero no vemos en esos capítulos referencias a este punto concreto y, de otra parte, nos parece que las muestras de juicios diferentes sobre la figura de Augusto, incluidos los negativos, Tácito no las sitúa en el Senado sino en la calle.

${ }^{94}$ En la terminología que la crítica literaria utiliza para referisrse a la estructura de las Vitae suetonianas y a la segmentación del contenido de las mismas observamos muchas veces una cierta ambigüedad. En efecto, se usan los términos de 'secciones/sectores', 'partes' (término utilizado por Suetonio precisamente en su
} 
la personalidad y significado de éste han quedado ya dibujados y expresados en el relato de su vida, incluidos, por supuesto, tanto el significado político como, en menor medida, el personal del protagonista. Es, pues, natural que Suetonio, en el relato de ese funeral, y al revés que Tácito, no se refiera, ni siquiera de forma alusiva, a los hechos y valoraciones que ya había ofrecido a lo largo de toda la Vita Augusti y que por tanto sus lectores conocen ${ }^{95}$. De este modo, expuesta la vida y muerte del protagonista, solo se detendrá en otros dos hechos importantes: el funeral del héroe y su testamento ${ }^{96}$.

Así, pues, el relato del funeral constituye para el biógrafo latino, según decimos, tan solo una rúbrica. Para situarla y calibrarla recordemos que los funerales del protagonista constituyen un ingrediente frecuente pero de importancia y extensión muy variable en la biografía política de la antigüedad clásica ${ }^{97}$. De otra parte, la Vita Augusti es, con diferencia, la Vida más extensa de la serie de las Vitae Caesarum ${ }^{98}$. Congruente con este hecho es, pues, que esta Vida sea también la que contiene un mayor número de rúbricas en la sección dedicada a la muerte del protagonista, juntamente con las Vidas de César, Tiberio y Claudio. Pero, a pesar de esto último, la presencia de esa rúbrica en la Vita Augusti es significativa, pues la noticia de los funerales en las vidas políticas de Suetonio solo la encontramos desarrollada, con la

Vita Augusti, cap.9), 'rúbricas' (species), sub-species, 'argumento' sin definición previa y a veces de modo intercambiable. Ambigüedad que, creemos, se arrastra ya desde la retórica antigua en la que esos mismos términos no tienen un uso idéntico y claro entre los diversos autores. Puede verse al respecto Ernesti (1983, sub vv. divisio, partitio, dispositio, distributio) o Lausberg (1975), en el cual conviene ver, además de los términos señalados, también el de pars. Y, en concreto para el concepto species y su uso en la retórica antigua (v. gr., Cicerón, Topica), cf. Pennacini (1985, pp.81-88).

${ }_{95}$ Así las referencias a: el numerus consulatuum (Ann.1.9 - Aug.26); el continuata...tribunicia potestas (Ann.1.9 - Aug.27.5); el aliaque honorum multiplicata aut nova (Ann.1.9 - Aug.26.1); el pietate erga parentem ... ad arma civilia actum (An., 9,3 - V. Aug., 10,1); el ille per libidines pessum datus sit (Ann.9.4 - Aug.17.1); el non aliud discordantis patriae remedium... (Ann.1.9.4 - Aug.28.1-2); el non regno tamen neque dictatura (Ann.1.9.5 - Aug.28.1-2 y 52-53); el legiones, provincias...conexa (Ann.1.9.5 - Aug.49); el modestiam apud socios (Ann.1.9.5 - Aug.47-48); el concitos per largitionem veteranos (Ann.1.10.1 Aug.10.3); el extortum invito senatu consulatum (Ann.1.10.2 - Aug.26.1); el caesis Hirtio et Pansa...copias occupavisse (Ann.1.10.2 - Aug.11.1); el divisiones agrorum... (Ann.1.10.2 - Aug.13.3); el sed Pompeium sed Lepidum...deceptos (Ann.1.10.3 - Aug.16.4); el Lollianas Varianasque clades (Ann.1.10.4 - Aug.23.1); el interfectos Romae Varrones (Ann.1.10.4 - Aug.19.1); el abducta Neroni uxor (Ann1.10.5 - Aug.62.2); el Nihil deorum honoribus relictum (Ann.1.10.6 - Aug.52).N.B.: Ofrezco este listado solo como muestra. Y cito los conceptos según la formulación de los mismos en Tácito prescindiendo, en aras de la brevedad, de la que hace Suetonio.

${ }^{96}$ Hecho este de la inclusión del testamento que no es extraño a la tradición biográfica. Con él acaba también Suetonio la Vita Tiberii y lo incluye asimismo la Vita Vergilii.

${ }^{97}$ En el caso de Nepote, aunque en varias Vitae se alude a los funerales del héroe, no se describe ninguno, lo que no es extraño dada la brevedad de aquéllas. Plutarco, por su parte, en bastantes ocasiones, presta atención a los funerales de sus biografiados, incluso en algunas ocasiones (Pelópidas, Filopemen, Numa, Coriolano, Publícola, Timoleón, Demetrio) de forma relativamente extensa. Y su narración, de carácter más abierto que la de Suetonio, ofrece los datos sobre los funerales envueltos o entremezclados con reflexiones morales, ya sobre el protagonista mismo ya sobre los sentimientos de respeto o admiración de la gente.

${ }^{98}$ Por orden de extensión decreciente las Vitae suetonianas se ordenarían así: Vita Augusti, V. Caesaris (que nos ha llegado incompleta), V. Tiberii, V. Neronis, V. Caligulae, V. Claudii, V. Vespasiani, V. Domiciani, V. Galbae, V. Vitellii, V. Otonis, V. Titii. 
entidad de una rúbrica, en dos casos: en la Vida de César, cuyos funerales se desarrollaron en circunstancias muy particulares, que les daban un especial significado, y en ésta de Augusto ${ }^{99}$. En el caso de la Vita Augusti la rúbrica en cuestión tiene entonces una especial relevancia. Y es que su presencia se debería a la conciencia que nuestro autor tenía del significado excepcional que la figura de Augusto suponía en la historia de Roma, conciencia que le llevó a componerla con particular detenimiento y esmero $^{100}$. Por ello la entidad de esta rúbrica es coherente con el diseño y propósito del autor para la Vita Augusti y, dentro de sus límites, refleja también el estilo y la personalidad intelectual de Suetonio. En efecto, a esta rúbrica, a pesar de su brevedad, no le falta un apunte de estructura. Suetonio, ciertamente, nos ofrece los hechos del funeral de forma lineal, siguiendo el orden cronológico pero a la vez agrupándolos en brevísimos apartados, estilísticamente diferenciados casi siempre solo por un recurso léxico mínimo, es decir, la primera palabra que, tras pausa fuerte, los encabeza: corpus para abrir la translatio cadaueris; senatus para la sección central, la sesión del Senado en que se proponen las honras fúnebres concretas; sección a la que sigue una brevísima transición a base de un adverbio adversativo seguido de un ablativo absoluto de valor temporal (uerum adhibito honoribus modo), transición que nos lleva desde ese apartado al de la celebración de las exequias (reliquias) para llegar al último momento, el de llevar las cenizas de Augusto al Mausoleo y la fórmula id opus (anafórico más sustantivo) para introducir la noticia sobre el Mausoleo, cuya mención (ac Mausoleo condiderunt) acababa de ocurrir cerrando el apartado anterior (Apdo. III), en realidad el último referido a la noticia suetoniana del funeral.

De otro lado, se puede ver que en esta unidad temática el biógrafo Suetonio muestra el afán informativo que le caracteriza, revelando un rasgo de su personalidad como escritor. Ciertamente nos transmite un número mayor que Tácito de hechos materiales acerca del funeral, en sentido amplio, como los referidos a la translatio cadaueris o los referentes al Mausoleo. Y también, como veíamos atrás, más datos de propuestas relativas a los rituales del funeral, del luctus publicus y de los honores a tributar a Augusto como los referidos a la estatua de la Victoria, al canto fúnebre (nenia), al cambio de anillos, a quiénes deberían recoger los últimos restos, al cambio del mes llamado augustus, a que toda la época de la vida de Augusto sea llamada saeculum Augustum y, después, ya en el desarrollo de las exequias, a las laudationes,

\footnotetext{
99 En las demás Vitae o no se dice nada al respecto (así ocurre en las de Vitelio, Tito y Domiciano); o los funerales, a veces privados, son tan solo aludidos, no narrados o descritos (así es en las de Tiberio, Calígula, Claudio, Nerón, Galba, Otón y Vespasiano).

${ }^{100}$ Cualquier lector atento de las Vidas de Suetonio puede observar que la de Augusto es la más larga y más completa. Y con algo más de atención caerá en la cuenta de que es también la mejor construida. Esta cualidad la observó ya, y la explicitó, uno de los primeros y principales estudiosos de Suetonio, Schmidt (1891, p.33). En efecto, ya en 1891, afirmaba: «in exponendis autem de his singillatim iudiciis ab Augusti biographia exeamus atque reliquas ad illam revoquemus; nam omnium iudicio et optime est digesta et ceterae ex illa quodammodo pendent». Y los estudios que han seguido sobre Suetonio y sobre la Vita Augusti muestran una coincidencia prácticamente unánime en esta misma valoración.
} 
a quiénes transportaron su cadáver desde el Foro al Campo de Marte, al juramento del uir praetorius sobre el águila que desde la torre de la pira asciende al cielo, y a quiénes, finalmente, recogieron sus cenizas.

Pero seguramente no lo mueve a ello solo el afán informativo del erudito. A la vez que ese afán Suetonio querría dejar patente la magnificencia del funeral de Augusto. Por ello ya de entrada afirma que los senadores pugnaban entre sí por ir lo más lejos posible en los honores fúnebres a tributar al emperador (senatus et in funere ornando et in memoria honoranda eo studio certatim progressus est ut...). Y ello hará también que varios de los hechos que nos refiere sean los más llamativos desde el punto de vista del boato, de la teatralidad, la solemnidad y el simbolismo, utilizando además en la presentación de los mismos, y con el fin de enfatizarlos, el recurso estilístico de la gradatio. Seguramente Suetonio, al elaborar su relato del funeral, tendría la conciencia de que el lector percibiría que, en correspondencia con la vida del protagonista, el funeral de Augusto había sido extraordinario por la acumulación de hechos referentes a esas solemnidad y teatralidad simbólicas. Él no confiesa que su propósito, al elaborar esta rúbrica, haya sido llevar al lector esa idea pero es más que verosímil que la tuviera in mente en esos momentos ${ }^{101}$.

Muy de otro modo, al componer sus Anales, Tácito se propone dar cuenta de la historia del principado en la etapa julio-claudia ${ }^{102}$, así como del nuevo régimen político cuya imagen y valoración irá plasmando ante el lector a lo largo de su obra de un modo crítico y pesimista ${ }^{103}$, teniendo como eje central el continuo antagonismo entre la libertas y la dominatio. Para ello nuestro autor se traza un plan claro: comenzará por ofrecer una rápida síntesis del principado de Augusto, centrándose, sobre todo, en el último periodo de su reinado (pauca et extrema); después se ocupará de los cuatro reinados siguientes, los cuales historiará, de acuerdo a la técnica analística, siguiendo el orden cronológico, año a año, y ya de forma plena y pausada: inde consilium mihi pauca de Augusto et extrema tradere, mox Tiberii principatum et cetera sine ira et studio quorum causas procul habeo (Ann.1.1). Y es que Tácito, de un lado, siente la necesidad de dejar claro al lector de sus Anales el origen del principado y del nuevo régimen político ${ }^{104}$. Y, de otro lado, tiene la esperanza de historiar in extenso, en una

\footnotetext{
${ }^{101}$ Sobre la simpatía con que Suetonio ve el régimen del principado en general y la figura de Augusto en particular puede verse Cizek (1977, pp.147 y 178). Recordemos, sin embargo, que Suetonio es, con todo, bastante objetivo en sus Vidas y que en concreto en la de Augusto nos ofrece no solo los aspectos positivos sino también los negativos, aunque los primeros predominan.

${ }^{102}$ Un primer acercamiento a la finalidad, organización (héxadas y tríadas) e hilos conductores que proporcionan la unidad que, como obra literaria, tienen los Anales puede verse en Pippidi (1938, pp.233-297)

${ }^{103}$ Pesimismo que se observa creciente en la secuencia cronológica de las obras de Tácito y que tiene su expresión máxima en los Anales según ha puesto de relieve Ceaucescu (1974, pp.196-197). La tesis tradicional quiere ver una causa fundamental para ese pesimismo en la defraudación que el principado de Trajano, pretendido émulo de Augusto, había causado a Tácito. Esta tesis la expuso en primer lugar Willrich (1927, pp.54-78). A ella se han sumado después varios estudiosos, entre ellos Velaza (1993, pp.335-356).

104 Que para Tácito la historia no solo ha de contar las cosas sino también interpretarlas y explicarlas queda claro por la declaración de intenciones que hace al inicio de sus Historiae: Ceterum antequam destinata componam, repetendum videtur qualis status urbis, quae mens exercituum, quis habitus provinciarum, quid in
} 
obra posterior, el reinado de Augusto ${ }^{105}$; la solución a su dilema vendrá al dedicar ahora al reinado de Augusto solamente una apretada síntesis. Por tanto, siguiendo su plan, Tácito resume de modo muy conciso el acceso al poder de Augusto (cap.2) para pasar de inmediato a sus últimos años, sus planes de sucesión, que implican hacer de facto hereditario el Principado, y su muerte (caps.3-5).

Pero lo que Tácito no hace en los capítulos ahora citados es la valoración global de la obra política de Augusto, y del significado de éste. Para ello Tácito podía elegir entre diversas vías ${ }^{106}$. Una de ellas, lógica, y muy practicada por él en otras ocasiones, podía ser la del retrato directo, no colocado en boca de los demás, y dado tras la noticia de la muerte del personaje, pero no dentro del relato de los funerales. Sin embargo ahora Tácito, de un lado, utiliza según vimos, el recurso de los rumores, una aparente suma de los diferentes juicios que la opinión pública hacía de la vida política de Augusto; y, de otro lado, nuestro autor decide insertar ese retrato y valoración políticos dentro del relato del funeral. Y ello sucede en esos caps. 8-10 del libro I de los Anales $^{107}$. Esto hará que el relato tacitiano del funeral de Augusto, al incluir aquella apretada síntesis valorativa de su reinado, sea necesariamente más amplio y, según vimos ya, mucho más complejo que la atrás analizada rúbrica de Suetonio. En este contexto es natural que para empezar, a Tácito le importen poco aquellos rituales del funeral o del luctus publicus, atrás mencionados, que se pueden esperar en un funus imperatorium, debiendo suponer, según dijimos, que todo esto lo tiene in mente al escribir sepultura more perfecta. En ese orden de cosas más significado, en principio, podría tener la ausencia de la translatio cadaueris, atrás examinada, y de cualquier alusión al Mausoleo, por el importante significado político que éste encerraba proveniente de su fecha de construcción, de su forma, de su grandiosidad y de la intención de Augusto al construirlo ${ }^{108}$. Pero, dada la velocidad que para las

toto terrarum orbe validum, quid aegrum fuerit, ut non modo casus eventusque rerum, qui plerumque fortuiti sunt, sed ratio etiam causaeque noscantur (Hist.1.4).

${ }^{105}$ Hablando de los asuntos internos del año 20 d.C., Tácito (Ann.3.24) escribe: ut valida divo Augusto in rem publicam fortuna, ita domi improspera fuit ob impudicitiam filiae ac neptis quas urbis depulit, adulterosque earum morte aut fuga punivit... sed aliorum exitus simul cetera illius aetatis memorabo, si effectis in quae tetendi plures ad curas vitam produxero. Según esto, Tácito contaba con historiar el reinado de Augusto in extenso, si el tiempo de su vida le daba lugar para ello. Sobre este asunto puede verse: Syme (1958, p.476).

${ }^{106}$ Rambaud (1970, pp.417-447) pone de relieve que la historiografía latina, encabezada en esto por Salustio, a la hora de realizar el retrato de personajes prefiere, sobre todo, dos lugares: primero, tras el relato de la muerte del protagonista o, en segundo lugar, antes de comenzar el relato de sus hechos.

107 En medio de la noticia de la muerte de Augusto (cap.5) y de sus funerales han quedado los caps.6 y 7, en los que el autor se ha ocupado ya del 'inicio' del principatum Tiberii. De modo que los caps.8-10 (sobre todo 9-10) suponen como un alto en la narración, ya iniciada, del Principado de Tiberio para retomar en ellos el tema de Augusto. Esta aparente ruptura de la linealidad temática se inscribe seguramente en el carácter especial de los caps.1-15 del 1. I de los Anales, que en palabras de Leeman (1973, p.199) se caracterizan por una transición gradual entre la mise-au-point del cap.1 y la narración propiamente dicha, que comenzaría en cap.16. Por su parte, Codoñer (1999, pp.80 y 82) defiende una ligazón básica que, por debajo de la aparente ruptura, hay entre los caps. 9-10 y los anteriores del libro I de los Anales; más en concreto piensa que los caps.9-10 enlazan con el cap. 2 y vendrían a ser un comentario, bajo la forma de rumores, de los hechos aludidos en este capítulo.

${ }_{108}$ Entre la variada bibliografía que se ha ocupado del Mausoleo queremos citar: Zanker (1992, pp.97-102); Arce (1988, pp.59-72); Davies (2000. pp.13-19 y 137-142). 
cosas de Augusto, Tácito se había impuesto, es algo que se comprende bien. Sin embargo en lo que, a pesar de esa velocitas, sí se fija el Tácito historiador, que compone su obra con la intención antes señalada, es en los hechos que tienen una importante significación política: el ya señalado juego Senado - Tiberio a la hora de aprobar las propuestas de los honores fúnebres y a la hora de la presentación por Messala del aquí extraño juramento in nomen Tiberii, el edicto de Tiberio prohibiendo que la cremación del cadáver se hiciera en el Foro en vez de en el Campo de Marte, la para Tácito injustificada prevención de Tiberio a desórdenes públicos durante el funeral, la reacción del pueblo ante el despliegue militar para defender lo que no corría peligro (el orden y el nuevo régimen de poder personal) y, sobre todo, los supuestos comentarios de la gente sobre la figura de Augusto que, según vimos, es el medio que Tácito usa para, en realidad, llevar al ánimo del lector lo que probablemente es su juicio sobre el mismo; a todo lo cual se añade al final la noticia sobre la consecratio. En este contexto, y dentro de la brevedad, la mirada de Tácito, historiador y filósofo de la vida política, será en este relato necesariamente más amplia y más profunda: le preocupa toda Roma y todo lo que Augusto significó para Roma. Y, con gran habilidad literaria, es capaz de poner ante los ojos del lector a su Augusto en el relato del funeral del mismo.

Ahora bien, ¿es disonante que en una obra historiográfica del género Annales se incluya la valoración política global de Augusto en el relato de su funeral? Realizar tales retratos y valoraciones de los protagonistas con ocasión de la noticia de su muerte es, según apuntamos antes, algo natural y, como tal, propio del género de la historia antigua ${ }^{109}$. Así lo hicieron, en un grado u otro, muchos de los historiadores de la Antigüedad: Tucídides, Jenofonte, Polibio, Salustio, T. Livio y otros según podemos ver en sus obras y según constataba ya Séneca el Rétor en su Suasoria $\mathrm{VI}^{110}$. Y el propio Tácito realiza esos retratos y valoraciones con frecuencia, por ejemplo, en los casos de Livia (Ann.5.1-2), Tiberio (Ann.6.51) o Galba (Hist.1.49), retratos y valoraciones que, con ocasión de la noticia de la muerte ${ }^{111}$, hace como extrayendo la conclusión que se deriva de los actos que del protagonista han sido o narrados o aludidos previamente. Por tanto desde el lado de la tradición del género historiográfico la presencia del retrato político de Augusto por Tácito en sus Anales poco después de haber dado cuenta de su muerte (cap.5) cuadra bien en su obra. Pero también es verdad que este retrato del Augusto político es de mayor entidad, no sigue el esquema habitual, el cual puede verse, por ej., en el de Tiberio o en el de

\footnotetext{
109 Un recorrido por los «Death notice» en la historiografía antigua puede verse en Pomeroy (1991). Para los historiadores griegos disponemos de una breve referencia sobre este punto en Wardman (1971, p.257).

110 Allí dice: Quotiens magni alicuius (viri) mors ab historicis narrata est, totiens fere cosummatio totius vitae et quasi funebris laudatio redditur. Hoc semel aut iterum a Thucydide factum, item in paucissimis personis usurpatum a Sallustio, T. Livius benignus omnibus magnis viris praestitit. Sequentes historici multo id effusius fecerunt. Woodman (1977, p.40, n.2) piensa que entre ellos estaría también Cremucio Cordo, Aufidio Basso y Asinio Polión. Y Pomeroy (1991, p.123) resalta el sorprendente olvido que Séneca tuvo en esta ocasión de Jenofonte y Polibio.

111 Para los obituarios en Tácito, $c f$. Syme (1970, p.79-90).
} 
$\mathrm{Galba}^{112}$, y se construye en base a ciertos recursos retóricos, ya examinados (controversia in utramque partem, rumores, uso del innuendo), que en el caso de Tiberio o de Livia o están ausentes o carecen de la importancia que ahora tienen. Todo ello le confiere un status especial. Y, sobre todo, debemos recordar que nuestro autor lleva a cabo este juicio y valoración de Augusto no a continuación de su muerte o de sus funerales sino integrándolo en el relato de éstos. Pensamos que tal integración, en principio llamativa, en la pluma de Tácito no deja de ser una elección afortunada y un acierto por cuanto la ocasión era especialmente propicia para uno de sus propósitos: que el juicio sobre Augusto fuera puesto en boca de otros. En efecto, ¿qué cosa hay más natural que, con ocasión de los funerales, se hable del muerto y se enjuicie su vida? Aunque, de otro lado, ello supusiera como un alto en la marcha de la narración de los hechos del funeral, según revela el ceterum con que el autor, por una parte, cierra el texto dedicado a las opiniones valorativas de Augusto y, por otra $^{113}$, vuelve a enlazar con el relato de las exequias tomado este término en sentido amplio. En cualquier caso creemos que, al proceder así, nuestro historiador Tácito se nos revela, también en esto, creativo y original ${ }^{114}$.

Así, pues, el estudio comparativo entre los relatos que del funeral de Augusto nos ofrecen Suetonio y Tácito pone de relieve grandes diferencias; diferencias que hemos tratado de explicar, en primer lugar, por el distinto género literario en que aquel relato se inscribe, pero al mismo tiempo por la intención y diseño particular de cada una de las obras, a lo cual se suma la distinta personalidad intelectual de uno y otro autor.

\section{REFERENCIAS BIBLIOGRÁFICAS}

Ailloud, H. (1989), Suétone. Vies des douze Césars, I, César-Auguste, París, Les Belles Lettres $\left(1931^{1}\right)$.

Alexander, W.H. (1952), «The "psychology" of Tacitus», CJ 47, 326-328.

ARCE, J. (1988), Funus imperatorum. Los funerales de los emperadores romanos, Madrid, Alianza.

Aubrion, E. (1991), «L'eloquentia de Tacite et sa fides d'historien», ANRW II.33.4, Gruyter, pp. 2597-2688.

\footnotetext{
112 En sus obituarios se recuerdan los principales datos de su trayectoria biográfica, comenzando por el origen familiar, y se dan después rápidos trazos de su vida política y de su carácter.

${ }^{113}$ Sin duda esta doble función tiene su reflejo externo y ecdótico en el hecho de que muchos editores utilicen el punto y aparte para separar el parágrafo introducido por el ceterum del resto del texto del capítulo.

${ }^{114}$ De todas formas volvemos a encontrar esta técnica literaria usada por Tácito en Annales 2.73. En ese capítulo de los Anales Tácito realiza la valoración, tanto en el aspecto personal como en el político, de la figura de Germánico. Esta valoración absolutamente laudatoria la lleva a cabo realizando una synkrisis entre la figura de Germánico y, nada menos, la figura de Alejandro Magno. Pero lo que ahora nos importa recalcar es que, como en el caso de Augusto, Tácito utiliza el recurso de dar tal valoración como comentarios de la gente que asiste al funeral (funus sine imaginibus et pompa per laudes ac memoriam eius celebre fuit. Et erant qui...), por tanto dentro del relato del mismo.
} 
BALDwin, B. (1983), Suetonius, Amsterdam, Hakkert.

BArdon, H. (1953), «Sur Tacite psychologue», Anales de Filologia Clásica 4, 19-35.

BenARio, H.W. (1990), «Six years of Tacitian studies. An analytic bibliography on the Annales (1980-1986)», ANRW II.33.2, pp.1477-1498.

BERANGer, J. (1953), Recherches sur l'aspect idéologique du principat, Basilea, Reinhardt.

Brelich, A. (1938), Trionfo e morte, Bolonia, Zanichelli.

CARY, E. (1968), Dio’s Roman History, t. 8, Londres, Loeb.

Ceaucescu, P. (1974), «L'image d'Auguste chez Tacite», Klio 56, 183-198.

CizeK, E. (1977), Structures et idéologies dans Les Vies des Douze Césars, París, Les Belles Lettres.

Codoñer, C. (1999), «Los primeros capítulos de los Annales de Tácito», Corona spicea: in memoriam Cristóbal Rodríguez Alonso, Oviedo, Universidad de Oviedo, pp.79-90.

Cortés Copete, J.M. (2011), Dión Casio. Historia Romana, libros L-LX, Madrid, Gredos.

Cousin, J. (1951), «Rhétorique et psychologie chez Tacite», REL 29, 228-247.

DAITZ, S.G. (1960), «Tacitus’ technique of character portrayal», AJP 81, 30-52.

DAVIES, P.J.E. (2000), Death and emperor. Roman imperial funerary monuments from Augustus to Marcus Aurelius, Cambridge, Cambridge University Press.

Develin, R. (1983), «Tacitus and techniques of insidious suggestión», Antichton 17, 64-95

ERnesti, J. CH. G. (1983), Lexicon Technologiae Latinorum Rhetoricae, Hildesheim, Olms $\left(1798^{1}\right)$.

Fabia, Ph. (1967), Les sources de Tacite dans les Histories et les Annales, Roma, Colin.

Ferrero, L. (1946), «La voce publica nel proemio degli Annali di Tacito», RFIC 24, 50-86.

Fisher, C.D. (1966), Cornelii Taciti Annalium ab excessu divi Augusti libri, Oxford, Oxford University Press $\left(1906^{1}\right)$.

Fourneaux, H. (1896²), P. Cornelii Taciti Annalium ab excessu divi Augusti libri. The Annals of Tacitus, 1-6, Oxford, Oxford University Press.

Fraschetti, A. (1990), Roma e il Principe, Bari, Laterza.

FunAioli, G. (1931), «C. Tranquillus Suetonius», RE 4.1, cols. 593-641.

Galand-Hallyn, P. (1991), «Bibliographie suétonienne (Les Vies des XII Césars) 19501988. Vers une réhabilitation», $A N R W$ II.33.5, Gruyter, pp. 3576-3619.

GASCOU, J. (1984), Sueton historien, Roma, École Française.

Gerber, A. - Greef, A. (1962), Lexicon Taciteum, Hildesheim, Olms (1877-1890¹).

Giner, M.G. (1983), «Elementos del finis vitae», en Oroz RetA, J. (ed.), Helmantica, Corollas philologicas in honorem Joseph Guillén, Publ. Univ. Pontificia, pp.229-246.

GonzÁlez, J. (2002), Tácito y las fuentes documentales: ss.cc. de honoribus Germanici decernendis (Tabula Siarensis) y de Cn. Pisone Patre, Sevilla, Universidad de Sevilla.

Goodyear, F.R.D. (1972), The Annals of Tacitus, vol.I, Cambridge, Cambridge University Press.

Goodyear, F.R.D. (1981), The Annals of Tacitu, vol.II, Cambridge, Cambridge University Press.

Grenade, P. (1961), Essai sur les origines du principat. Investiture et renouvellement des pouvoirs imperiaux, París, E. de Boccard.

Grimal P. (1973), Suétone, Vies des douze Césars, París, Le Livre de Poche. 
GugEL, H. (1977), Studien zur biographichen technik Suetons (Aus dem Nachlaß herausgegeben von K. Vretska), Wien-Köln-Graz, Hermann Böhlaus.

Guillén, J. (1977), Vrbs Roma. I, La Vida Privada, Salamanca, Ediciones Sigueme.

HAVERFIELD, F. (1912), «Four notes on Tacitus», JRS 2,195-200.

Hellegouarch'C, J. (1963), Le vocabulaire latin des relations et des partis politics sous la Republique, París, Les Belles Lettres.

Hinojo, G. - Lorenzo, J. - Moreno, I. (1979), «Historiografía latina. Tácito, Annales I,4-6» en Codoñer, C. (coord.), El comentario de textos griegos y latinos, Madrid, Cátedra, pp.221-248.

HinOJO, G. (1987), «Alusiones y designaciones del sistema republicano en Tácito», Veleia 4, pp.291-317.

Hohl, E. (1993), «Wann hat Tiberius das Principat übernommen», Hermes 68, 105-115.

Huntington-Metcalf, P. (1979), Celebrations of Death, Cambridge, Cambridge University Press.

Koestermann, E. (1961), «Der Eingang der Annalen des Tacitus», Historia 10, 330-335.

Koestermann, E. (1963), Cornelius Tacitus, Annalen, bd. I, Buch 1-3, Heidelberg, Carl Winter Universitatsverlag.

Lausberg, H. (1975), Manual de Retórica Literaria, trad. esp., Madrid, Gredos.

LE GALL, J. (1990), «Le serment à l'empereur: une base meconnue de la tyrannie imperiale sous le Haut Empire» en C. NiCOLET, Du pouvoir dans l'Antiquité: mots et realités, Ginebra, Droz, pp. 165-180.

LeEman, A.D. (1973), «Structure and meaning in the prologues of Tacitus», Yale Classical Studies 23, 169-208.

Lenchantin, M. (1938), «Augusto e Tacito», RFIC, n.s. 17, 337-345.

LORD, L.E. (1927), «Note on Tacitus' summary of the reign of Augustus», The Classical Review 41, 121-122.

Lounsbury, R. C. (1987), The arts of Suetonius. An introduction, Nueva York, P. Lang.

Miller, N.P. (1969), «Style and content in Tacitus», en Dorey, T.A. (ed.), Tacitus, Londres. Routledge, pp. 99-116.

NewBALD, R. F. (1976), «The uulgus in Tacitus», Rheinisches Museum 119, 85-92.

Nicolet, C. (1990), Du pouvoir dans l'Antiquité: mots et realités, Ginebra, Droz, pp. 53-67.

Pagán, V.E. (ed.) (2012), A companion to Tacitus, Malden-Oxford, Blackwell.

Paladini, M.L. (1965), «Nota Tacitiana», Latomus 24.3, 629-632.

PAOLI, U.E. (1964²), Urbs, trad. esp., Barcelona, Iberia.

Paratore, E. (1959), «Claude et Neron chez Suétone», RCCM 1, 326-341.

Pennacini, A. (1985), «Strutture retoriche nelle biografie di Suetonio», en Retorica e Storia nella cultura classica, a cura di PenNAcini, P., Bologna, Pitagora, 81-88.

PiCIRILLI, L. (1998), «I testi biografici come testimonianza della storia della mentalità», en EHLERS, W. W. (coord.) La biographie antique. Huit exposés, Entretiens sur l'Antiquité Classique 44, Vandoeuvres-Genéve, Fondation Hardt.

PIPPIDI, D.M. (1938), «Tacite et Tibère. Une contribution à l'étude du portrait dans l'historiographie latine», Ephemerides Daco-romana 8, 233-297 (ahora en id., Autour de Tibère, Bucarest, 1944 y Roma, 1965).

Plácido, D. (2004), Dion Casio, Historia Romana, libros 1-35, Madrid, Gredos. 
Pomeroy, A. (1991), The appropiate comment. Death notices in the ancient historians, Frankfurt am Main-Nueva York, Lang.

RAMBAUD, M. (1970), «Recherches sur le portrait historique dans l'historiographie romaine», LEC 38, 417-447.

RichARD, J.-C. (1978), «Recherches sur certains aspects du culte imperial: les funerailles des empereurs romains aux deux premiers siècles de nôtre ère», $A N R W$ II.16.2, Gruyter, pp.1121-1134.

RoldÁn, J. M. (2008), Césares, Madrid, Esfera de los libros.

RyBerg, I.S. (1942), «Tacitus' art of innuendo», TAPA 73, 383-404.

SAncho Royo, A. (1985), Apiano, Historia romana II. Guerras civiles, Madrid, Gredos.

SCHEID, J. (1984), «Contraria facere: renversement et déplacement dans les rites funeraires», AION (Arch.). 6, 117-139.

Schmidt, G. (1891), De Romanorum imprimis Suetonii arte biographica, Marpurgi Catorum. Kessinger Publishing (2010).

SHATZMAN, I. (1974), «Tacitean rumores», Latomus 33, 549-578.

Shotter, D.C.A. (1967), «The debate on Augustus (Tacitus, Annals, 1, 9-10)», Mnemosyne, ser. 4, 20.2, 171-174.

Stegmann de Pritzwald, C. (1968), Vellei Paterculi ex Historiae romanae libris duobus quae supersunt, Stuttgard, Teubner (ex ed. 1933²).

STEIDLE, W. (1963), Sueton und die antike Biographie, Munich, Beck.

Suerbaum, W. (1990), «Zweiundvierzig Jahre Tacitus Forschung: systematiche Gesamtbibliographie zu Tacitus’ Annalen 1939-1980», ANRW II.33.2, pp.1032-1476.

Syme, R. (1958), Tacitus, I, Oxford, Oxford University Press.

Syme, R. (1970), Ten studies in Tacitus, Oxford, Oxford University Press.

Syme, R. (1977), «How Tacitus wrote Annals I-III», Historiographia Antiqua, Mélanges W. Peremans, Lovaina, Lovaina University Press, pp. 230-263.

TAlBeRT, R.J.A. (1984), The senate of imperial Rome, Princeton, Princeton University Press.

Torres Esbarranch, J. J. (1985), Herodiano. Historia del Imperio Romano después de Marco Aurelio, Madrid, Gredos.

Urban, R. (1979), «Tacitus und die Res Gestae divi Augusti. Die Auseinandersetzung des Historikers mit der offiziellen Darstellung», Gymnasium 86, 59-74.

VALCÁRCEL, V. (2009), «La ambigua relación entre la biografía y la historia», en VALCÁRCEL, V. (ed.), Las Biografía griega y latina como género literario. De la Antigüedad al Renacimiento. Algunas calas, Vitoria-Gasteiz, Universidad del País Vasco, pp. 19-39.

VelaZA, J. (1993), «Tácito y Augusto. (Ann., I, 9-10)», Emerita 61, 335-356.

VelazA, J. (1996), «Remisit Caesar adroganti moderatione. (Tácito, Ann., 1.8)» Latomus 55.4, 863-869.

VERSNEL, H.S. (1980), «Destruction, devotio and despair in a situation of anomy: the mourning for Germanicus in triple perspective», en Perennitas. Studi in onore di Angelo Brelich (Promossi dalla Cátedra di Religioni del mondo classico dell’Università degli studi di Roma), Roma, Ateneo, pp.541-618.

VollmeR, F. (1892-1893), «De funere publico romanorum», Jahrbücher für Klassische Philologie, Suppl., n.s. 19, 320-364. 
WAELE, E. DE (1930), «Quo animo Tacitus “sive” particula usus sit», Mnemosine, n.s. 58.3, 309-317.

Wallace-Hadrill, A. (1983), Suetonius. The Scholar and his Caesars, Yale, Yale University. WARdMAn, E.A. (1971), «Plutarch's methods in the Lives», CQ, n.s. 21, 254-261.

Weinstock, S (1971), Divus Julius, Oxford, Clarendon Press.

Wellesley, K. (1967), «The dies imperii of Tiberius», JRS 57, 23-30

WhitehEAD, D. (1979), «Tacitus and the loaded Alternative», Latomus 38, 475-495.

Willrich, H. (1927), «Augustus bei Tacitus», Hermes 62, 54-78.

WölfFlin, E. (1867), «Jahresberichte über Tacitus», Philologus 25, 92-134.

Woodman, A. J. (1977), Veleius Paterculus. The Tiberian narrative (2. 94-131), Cambridge, Cambridge University Press.

Woodman, A. J. (2002), «Not a funeral Note: Tacitus, Annals I, 8, 5-6», CQ, n.s. 52. 2, 629632.

Wuilleumeur, P. (1978), Tacite. Annales, Livres I-III, Texte établi et traduit, $2^{\mathrm{a}}$ ed., París, Les Belles Lettres.

ZANKer, P. (1992), Augusto y el poder de las imágenes, trad. esp., Madrid, Alianza.

\section{APÉNDICE I: ESQUEMA COMPARATIVO DE AMBOS RELATOS}

\section{Suetonio, Aug., cap.100}

Apartado I. Traslado del cadáver de Nola a Roma.

Apartado II. Propuestas y discusión en el Senado de las honras fúnebres: Senatus et in funere ornando et in memoria honoranda eo studio certatim progressus est ut inter alia complura censuerint...

1. Quidam funus triumphali porta ducendum...

2. Praecedente Victoria quae est in curia.....

3. Dato ausente

4. Dato ausente

5. Dato ausente

6. Dato ausente

7. Dato ausente

8. Canentibus neniam...

9. Alii ponendos anulos aureos...

10. Nonnulli ossa legenda per sacerdotes...

Cuadernos de Filología Clásica. Estudios Latinos 2015, 35, núm. 1 43-77

\section{Tácito, Ann.1., caps.8-10}

I. Apartado ausente

II. Propuestas y discusión en el Senado de las honras fúnebres: cap.8: Tum consultatum de honoribus, ex quis qui maxime insignes visi...

1. Ut porta triumphali duceretur funus...

2. Dato ausente

3. Gallus Asinius ut legum latarum tituli...

4. Victarum ab eo gentium vocabula anteferrentur L. Arruntius.

5. Addebat Messsala renovandum... sacramentum...

6. Interrogatusque (Messala) a Tiberio (intervención de Tiberio)

7. Ea sola species adulandi... (opinión auctorial).

8. Dato ausente

9. Dato ausente

10. Dato ausente 
11. Apellationem mensis Augusti in Sept...

12. Alius ut omne tempus....Saeculum Augustum appellaretur

13. Dato ausente en este apartado, aludido en apartado III, $\mathrm{n}^{\circ} 4$

14. Dato ausente

15. Dato ausente

Apartado III. Celebración de las exequias: Verum adhibito honoribus modo...

1. Dato ausente

2. Dato ausente

3. Bifariam laudatus est... a Tiberio et a Druso

4. Senatorum umeris delatus in Campum..

5. Crematusque...

6. Nec defuit uir praetorius...

7. Reliquias legerunt primores equestris ordinis tunicati et discincti...

8. Et Mausoleo condiderunt...

Apartado IV. Apartado ausente

Apartado V. Apartado ausente, pero $c f$. $\mathrm{n}^{\circ} 6$ del Apdo. III (Nec defuit uir ...)

Apartado VI. El Mausoleo de Augusto:

1. Datación y ubicación.

2. Donación de su entorno hecha por Augusto para los romanos.
11. Dato ausente

12. Dato ausente

13. Conclamant patres corpus umeris senatorum...

14. Remisit Caesar adroganti moderatione (referido a la propuesta concreta y antes mencionada).

15. Populumque edicto monuit (Tiberius) ne in foro potiusquam in campo Martis, sede destinata...

III. Celebración de las exequias

1. Die funeris milites velut praesidio stetere.

2. Reacción del pueblo ante este hecho: multum inridentibus qui...

3. Dato ausente

4. Dato ausente en este apartado pero aludido en el apartado II, nº13-14.

5. Dato ausente aquí, pero señalado indirectamente en Apdo. I, nº15 (ne...cremari vellent)

6. Dato ausente, pero $c f$. Apdo. V

7. Dato ausente

8. Dato ausente

IV. Opinión de los romanos sobre el emperador a cuyo funeral asisten (caps.9-10): Multus hinc...sermo.

1. Opinión de los romanos no avisados (plerisque vana mirantibus, cap.9.1-2)

2. Opinión de los romanos avisados (apud prudentis)

a) Hechos invocados bajo el punto de vista positivo, cap.9. 3-5.

b) Hechos invocados bajo el punto de vista negativo, cap. 10 .

V. Consecratio o divinización de Augusto (cap.10.8): Ceterum sepultura more perfecta templum et caelestes religiones decernuntur.

VI. Apartado ausente.

1. Dato ausente.

2. Dato ausente. 


\section{APÉNDICE II: SOBRE LA INTERPRETACIÓN DE TÁCITO, ANN.1.8: REMISIT CAESAR ADROGANTI MODERATIONE}

Atrás dijimos que Tiberio, dominando en realidad la situación política en Roma ya en los días del funeral de Augusto, verosímilmente había denegado la petición de los senadores de llevar a hombros el cadáver de Augusto desde el Foro hasta la pira en el Campo de Marte. Queremos ahora aclarar el por qué de esa afirmación adelantando ya la matización de que aquella es una afirmación tenue, no exenta de dudas.

$\mathrm{Y}$ es que el valor de remisit en este pasaje tacitiano ha sido y es discutido proponiendo para él significados tan dispares como 'concedió' y su contrario 'negó' o 'rechazó'. Contradicción aparente que no es aclarada por el examen de los valores y usos de remittere tanto en su empleo general como en Tácito (Gerber - Greef (1962, sub v.), puesto que tal examen puede justificar uno y otro significado. Adelantemos también ya que el primero de ellos, 'concedió', es el mayoritarimente adoptado por los traductores mientras que el de 'rechazó' abunda más entre los comentaristas.

Por nuestra parte agruparemos las razones que pueden avalar uno u otro significado desde dos criterios distintos: el lingüístico-estilístico y el de realia o histórico.

El significado de 'concedió' desde el punto de vista lingüístico-estilístico encuentra dificultades que estimamos de peso. Para empezar ya el sintagma que lo acompaña, adroganti moderatione crea dificultades. En efecto la moderatio, a la que Tácito, en brillante oxímoron, califica de 'arrogante', insinúa que lo que hace Tiberio es rechazar un honor que quiere excesivo pues si el valor de remisit fuera el de 'conceder' no es tan fácil de entender que esa acción fuera hecha con moderatio ${ }^{115} \mathrm{Y}$ además a ello se añade otro hecho lingüístico-estilístico: la frase en cuestión (remisit adroganti moderatione) va unida a la siguiente con un -que copulativo: populumque edicto monuit ne vellent.... Ahora bien, esta última frase supone una semántica negativa (monuit...ne), de rechazo de otra posible pretensión, la que podía tener el pueblo de incinerar el cadáver de Augusto en el Foro en vez del Campo de Marte. Entonces parece lógico que la partícula -que, la cual en principio tiene un valor acumulativo y une un miembro de frase que continúa la idea expresada por el miembro anterior, esté uniendo dos hechos de la misma naturaleza, es decir, negativos, lo que invitaría a atribuir a remisit el significado de 'negar'. De lo contrario, se esperaría más bien una partícula adversativa para unir las dos frases en cuestión: «(Tiberio) concedió... pero advirtió / advirtiendo que no...»; esta secuencia se explica mejor que la de «concedió... y advirtió que no...».

De otro lado, desde el ámbito extralingüístico o histórico este valor de 'negar' para remisit tiene igualmente su apoyo: no es la única vez que Tácito nos presenta a Tiberio rebajando los honores fúnebres de los personajes más importantes y más

\footnotetext{
115 No se nos escapa que cabría entender el sintagma de adroganti moderatione como expresión pregnante queriendo decir Tácito que sí hizo la concesión a los senadores pero mostrándose superior y arrogante en ello y con la petición general de que se moderaran los honores. Pero esta segunda explicación parece más rebuscada.
} 
próximos a él, honores que se discuten en el ámbito político: así en el caso de su madre, Livia, nos dice Tácito (Ann.5.2): at Tiberius...honoresque memoriae eius (Liviae) ab senatu large decretos quasi per modestiam imminuit. $\mathrm{Y}$ en el caso de Germánico (Ann.3.5-6): Fuere qui publici funeris pompam requirerent compararentque quae in Drusum patrem Germanici honora et magnifica Augustus fecisset... Gnarum id Tiberio fuit; utque premeret vulgi sermones, monuit edicto multos inlustrium Romanorum ob rem publicam obisse, nemine tam flagrante desiderio celebratum; idque et sibi et cunctis egregium si modus adiceretur... ${ }^{116} \mathrm{Y}$ a este respecto se debe recordar que el honor que proponían los senadores para Augusto solo se había atribuido antes a Numa y a Sila ${ }^{117}$.

Por su parte el valor de 'concedió' para remisit encuentra un punto de apoyo inicial en la noticia de Suetonio, sobre esta cuestión, es decir, en un hecho extralingüístico. Y es que ese valor haría que la propuesta de los senadores que recoge Tácito (conclamant fratres corpus ad rogum umeris senatorum ferendum) casara bien con la afirmación de Suetonio: ac senatorum umeris (Augustus) delatus... in Campum. A este respecto no debe olvidarse, además, la buena información de que Suetonio dispone para esta Vita. De otro lado, contamos también con el testimonio de Dión Casio. Su noticia sobre los funerales de Augusto es ciertamente bastante amplia y explícita. Pero justo en este detalle su alusión no disipa todas las dudas. En efecto, primeramente (56.34.1-2) nos dice que «esta imagen (de Augusto) fue transportada desde el Palatino (al Foro) por los magistrados designados para el año siguiente» ${ }^{118}$, imagen que, por cierto, según nos dice, era de cera y en uniforme triunfal; tal imagen iría en el féretro que llevaba el cadáver. Y después (56.42.1) Dión Casio dice que «las mismas personas que antes habían portado el féretro lo hicieron pasar por la puerta triunfal ${ }^{119}$, se entiende camino del Campo de Marte. Ahora bien, Dión Casio no dice que tales portadores fueran específicamente senadores sino «los magistrados designados para el año siguiente», sin aclarar la clase o rango de los mismos. Según esto el historiador griego ni desmentiría ni confirmaría la afirmación de Suetonio de que el cadáver de Augusto fue transportado «a hombros de los senadores». Y contamos también con el testimonio de Herodiano a propósito del funeral de Septimio Severo, funeral alejado en el tiempo pero representativo del funus imperatorium en general. Y Herodiano (4.2) refiriéndose a quienes transportaron el cadáver de Septimio Severo hasta el Foro dice que fueron «los miembros más nobles del orden ecuestre y jóvenes

\footnotetext{
116 Esta noticia de Tácito se confirma por lo que al respecto nos dice la Tabula Siarensis: utique ageretur de ea re consilio Tiberii Caesaris Augusti principis nostri ideoque ab hoc ordine copia sententiarum ipsi fieret. Atqui is, adsueta sibi moderatione, ex omnibus iis honoribus, quos habendos esse censebat senatus, legerit eos quos ipse et Iulia Augusta mater..., satis apte posse haberi existumarent. Cf. González (2002, pp.299-310), cuya edición sigo, aunque no señalo los signos de reconstrucción.

117 Para Sila dice Apiano: «los senadores más robustos llevaron sobre sus espaldas el féretro (desde el Foro) y lo transportaron al Campo de Marte» (Guerras civiles, 1, 106, en Sancho Royo1985).

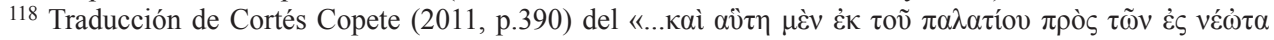

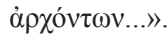

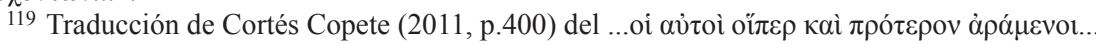


escogidos del orden senatorial» (Torres Esbarranch 1985, p.214); no dice, pues, que fueran exactamente senadores.

Estando así las cosas no es fácil definirse con contundencia por uno de los dos valores comentados para remisit. En nuestra opinión quizás pesan más los argumentos favorables a entender que lo que entonces hizo Tiberio fue negar la petición de los senadores ${ }^{120}$.

${ }^{120}$ Quiero recordar algunos nombres de los que han tratado esta cuestión, aunque de forma más bien breve: Fourneaux (1896, p.193,n.2); Wuilleumier (1978, p.12,n.3); Koestermann (1963, p.94); Paladini (1965, pp.629-632); Velaza (1996, pp.863-869). Por su parte, Goodyear (1972, pp.149-151) quiere ver compatible el valor de 'negar', que él acepta, para remisit, con la noticia de Suetonio y de Dión Casio (él piensa que tanto el autor latino como el griego se refieren a los mismos portadores del cadáver de Augusto). ¿Cómo? Goodyear dice que o bien Suetonio y Dión Casio se equivocan en este punto o los senadores ignoraron la negativa de Tiberio. Y de las dos alternativas él prefiere la segunda. 